OPEN ACCESS

Edited by:

Paolo Inglese,

Università degli Studi di Palermo, Italy

Reviewed by:

Brunella Morandi,

Università degli Studi di Bologna, Italy

Ahmad Arzani.

Isfahan University of Technology, Iran

${ }^{*}$ Correspondence:

Samuel Ortega-Farías sortega@utalca.cl

Specialty section:

This article was submitted to Crop and Product Physiology, a section of the journal Frontiers in Plant Science

Received: 05 March 2018 Accepted: 19 June 2018 Published: 12 July 2018

Citation:

Zúniga M, Ortega-Farías S,

Fuentes S, Riveros-Burgos $C$ and Poblete-Echeverría C (2018) Effects of Three Irrigation Strategies on Gas Exchange Relationships, Plant Water Status, Yield Components and Water Productivity on Grafted Carménère Grapevines. Front. Plant Sci. 9:992. doi: 10.3389/fp/s.2018.00992

\section{Effects of Three Irrigation Strategies on Gas Exchange Relationships, Plant Water Status, Yield Components and Water Productivity on Grafted Carménère Grapevines}

\author{
Mauricio Zúñiga ${ }^{1,2}$, Samuel Ortega-Farias ${ }^{1,3 *}$, Sigfredo Fuentes ${ }^{4}$, \\ Camilo Riveros-Burgos ${ }^{1}$ and Carlos Poblete-Echeverría ${ }^{5}$
}

\begin{abstract}
'Research and Extension Center for Irrigation and Agroclimatology, Universidad de Talca, Talca, Chile, ${ }^{2}$ Instituto de Investigaciones Agropecuarias, INIA Carillanca, Santiago, Chile, ${ }^{3}$ Research Program on Adaptation of Agriculture to Climate Change (A2C2), Universidad de Talca, Talca, Chile, ${ }^{4}$ School of Agriculture and Food, Faculty of Veterinary and Agricultural Sciences, The University of Melbourne, Melbourne, VIC, Australia, ${ }^{5}$ Department of Viticulture and Oenology, Faculty of AgriSciences, Stellenbosch University, Stellenbosch, South Africa
\end{abstract}

In the Chilean viticultural industry, Carménère is considered an emblematic cultivar that is cultivated mainly in arid and semi-arid zones. For this reason, it is necessary to use precise irrigation scheduling for improving water use efficiency (WUE), water productivity (WP), yield and wine quality. This study evaluated the effects of three deficit irrigation strategies on gas exchange variables, WUE, WP and yield components in a dripirrigated Carménère vineyard growing under semi-arid climatic conditions during two consecutive seasons (2011/12 and 2012/13). The irrigation strategies were applied in completely randomized design from fruit set $(S)$ to harvest $(H)$. The first irrigation strategy (T1) involved continuous irrigation at $100 \%$ of actual evapotranspiration $\left(E T_{a}\right)$ from $\mathrm{S}$ to the veraison $(\mathrm{V})$ period and at $80 \%$ of $\mathrm{ET}_{\mathrm{a}}$ from $\mathrm{V}$ to $\mathrm{H}$. The second irrigation strategy (T2) involved irrigation at 50\% of $\mathrm{ET}_{\mathrm{a}}$ from $\mathrm{S}$ to $\mathrm{H}$ and the third one (T3) involved no-irrigation from $\mathrm{S}$ to $\mathrm{V}$ and at $30 \%$ of $\mathrm{ET}_{\mathrm{a}}$ from $\mathrm{V}$ to $\mathrm{H}$. The results indicated that there was a significant non-linear correlation between net $\mathrm{CO}_{2}$ assimilation $\left(A_{N}\right)$ and stomatal conductance $\left(g_{s}\right)$, which resulted in three zones of water stress (zone $\mathrm{I}=\mathrm{g}_{\mathrm{s}}>0.30 \mathrm{~mol} \mathrm{H} \mathrm{O} \mathrm{m}^{-2} \mathrm{~s}^{-1}$; zone $\mathrm{II}=$ between 0.06 and $0.30 \mathrm{~mol} \mathrm{H}_{2} \mathrm{O} \mathrm{m}^{-2} \mathrm{~s}^{-1}$; and zone III $=g_{s}<0.06 \mathrm{~mol} \mathrm{H}_{2} \mathrm{O} \mathrm{m}^{-2} \mathrm{~s}^{-1}$ ). The use of less water by T2 and T3 had a significant effect on yield components, with a reduction in the weight and diameter of grapes. A significant increase in WP $\left(7.3 \mathrm{~kg} \mathrm{~m}^{-3}\right)$ occurred in T3, which resulted in values of WUE that were significantly higher than those from T1 and T2. Also, a significant non-linear relationship between the integral water stress $\left(\left.\mathrm{S}\right|_{\Psi}\right)$ and WP $\left(R^{2}=0.74\right)$ was established. The results show that grafted Carménère vines were tolerant to water stress although differences between cultivars/genotypes still need to be evaluated.

Keywords: Carménère vineyards, yield parameters, deficit irrigation, plant water status, water productivity 


\section{INTRODUCTION}

"Carménère" is considered one of the most important and emblematic cultivars for the Chilean wine production. The recent reintroduction of this cultivar is exclusive to Chilean production after disappearing from Europe in the XIXth century during Phylloxera spread (Jara-Rojas et al., 2015). Carménère is usually cultivated in arid and semi-arid regions that have low to no rainfall during the growing season, making this cultivar a relevant choice for adapting viticulture to water scarcity. For this reason, it is necessary to evaluate irrigation strategies for improving water use efficiency (WUE) and water productivity (WP) (Cifre et al., 2005; Möller et al., 2006; Ruiz-Sanchez et al., 2010; Medrano et al., 2015a). One of the most implemented strategies for improving WUE and WP is the regulated deficit irrigation (RDI), which has been widely tested in fruit trees (e.g., González-Altozano and Castel, 1999; Goldhamer and Beede, 2004; Goldhamer et al., 2006; Spreer et al., 2007; Ahumada-Orellana et al., 2017) and vineyards (e.g., McCarthy et al., 2002; Girona et al., 2006; OrtegaFarias et al., 2012; Romero et al., 2015). The RDI strategy keeps water replenishment below actual vineyard evapotranspiration $\left(\mathrm{ET}_{\mathrm{a}}\right)$ during phenological periods when vines are less sensitive to water stress, such as the veraison period. In veraison cell division stops but cell elongation begins (Fereres et al., 2003; Basile et al., 2011). There are several studies based on the effects of RDI implementation on yield, grape quality and WUE during preveraison (McCarthy et al., 2002; Poni et al., 2014), post-veraison (Intrigliolo et al., 2016) or both phenological periods (Chaves et al., 2007; Basile et al., 2011). Furthermore, the effects of RDI on gas exchange variables, such as stomatal conductance $\left(g_{s}\right)$, net assimilation $\left(\mathrm{A}_{\mathrm{N}}\right)$ and leaf transpiration (E) have been widely studied in vineyards (e.g., Ruiz-Sanchez et al., 2010; Santesteban et al., 2011; Romero et al., 2013; Intrigliolo et al., 2016; Merli et al., 2016).

Also, $g_{s}, A_{N}$ and $E$ are affected by environmental and specific vineyard characteristics such as atmospheric demand that varies throughout the season, soil type, cultivar, rootstock, and different viticultural practices including the use of cover crops (Medrano et al., 2015a,b). Considering all the aforementioned factors, the effects of RDI on final yield and grape quality depend first on the grapevine phenological stage at which RDI is applied and second on the severity of the stress imposed (McCarthy et al., 2002; Acevedo-Opazo et al., 2010; Romero et al., 2010). Due to the interaction of multiple site-specific factors, there is no single conclusion regarding the effects of RDI on yield parameters, WUE or WP (Intrigliolo and Castel, 2008; Uriarte et al., 2016). Therefore, it is necessary to evaluate the effect of water stress on gas exchange relationships, WUE and WP in Carménère vines specially under current water scarcity scenarios.

In order to conserve water, plants growing under a water restriction increase stomata closure which causes a decrease in the plant water potential and intensity of photosynthetic assimilation of $\mathrm{CO}_{2}$ (Rivero et al., 2009; Vineeth et al., 2016). Different researcher showed that $g_{s}$ is the earliest physiological factor to be affected under mild-to-moderate water stress conditions (Flexas et al., 2002; Medrano et al., 2002; Chaves et al., 2003; Cifre et al., 2005). Thus, three phases of $g_{s}$ responses to water stress have been previously described for mild $\left(0.5-0.7>\mathrm{g}_{\mathrm{s}}>0.15 \mathrm{~mol} \mathrm{H}_{2} \mathrm{O} \mathrm{m} \mathrm{m}^{-2} \mathrm{~s}^{-1}\right)$, moderate $\left(0.15>\mathrm{g}_{\mathrm{s}}>0.05 \mathrm{~mol} \mathrm{H}_{2} \mathrm{O} \mathrm{m}^{-2} \mathrm{~s}^{-1}\right)$ and severe $\left(\mathrm{g}_{\mathrm{s}}<0.05 \mathrm{~mol}\right.$ $\mathrm{H}_{2} \mathrm{O} \mathrm{m}^{-2} \mathrm{~s}^{-1}$ ) water stress (Medrano et al., 2002; Cifre et al., 2005; Jara-Rojas et al., 2015). Moreover, some limitations of biochemical reactions could negatively affect $A_{N}$ and reduce WUE for vines growing under severe water stress (Medrano et al., 2002; Cifre et al., 2005). However, obtaining accurate gs measurements under field conditions can be cost prohibitive due to specialized instrumentation requirements; intensive labor needed to achieve spatial variability of $g_{s}$, which requires qualified personnel to operate instruments and analyze data collection (Fuentes et al., 2012; Sepulveda-Reyes et al., 2016). As such, the monitoring of vine water status constitutes a suitable and affordable technique for properly achieving adequate levels of WUE and WP for sustainable grapevine production (Pellegrino et al., 2006; Acevedo-Opazo et al., 2010; Romero et al., 2013). In this sense, several studies have suggested the use of the stem water potential $\left(\Psi_{\mathrm{s}}\right)$, which has been shown to be a more reliable and representative parameter for determining wholeplant water status. Several studies indicated that $\Psi_{\mathrm{s}}$ is less variable and accurate enough to detect small but statistically significant differences among irrigation treatments compared to predawn and leaf water potential measurements (Choné et al., 2001; Lampinen et al., 2001; Williams and Araujo, 2002; Romero et al., 2010; Ahumada-Orellana et al., 2017). Similarly to $g_{s}$, vine water status responses to water stress have been reported within three thresholds: (i) mild ( $\left.\Psi_{\mathrm{s}}>-1.0 \mathrm{MPa}\right)$, (ii) moderate $\left(-1.0 \mathrm{MPa}>\Psi_{\mathrm{s}}>-1.2 \mathrm{MPa}\right)$ and (iii) severe water $\left(\Psi_{\mathrm{s}}<-1.4 \mathrm{MPa}\right)$ stress (Sibille et al., 2007; Van Leeuwen et al., 2009; Acevedo-Opazo et al., 2010). Based on these thresholds, there is no clear report relating the levels of vine water status with gas exchange responses in Carménère grapevines. Furthermore, the effects of water stress on yield, WUE and WP in Carménère grapevines also remain unevaluated. Hence, application of a correct RDI strategy for Carménère grapevines requires unified criteria between the $g_{s}$ and $\Psi_{s}$ levels of response to water stress; these unified criteria, in turn, would allow the acquisition of adequate results in terms of yield, WUE and WP. Thus, the aim of this study was to evaluate the effects of three irrigation strategies on the gas exchange relationships, vine water status, WUE, WP and yield components on grafted Carménère grapevines growing under Mediterranean climatic conditions. Also, the leaf gas exchange relationships were used to generated different water stress levels.

\section{MATERIALS AND METHODS}

\section{Study Site}

The experimental trial was located in a commercial vineyard in the Talca Valley in the Maule Region of Chile $\left(35^{\circ} 27,678^{\prime}\right.$ LS; $71^{\circ} 29,951^{\prime} \mathrm{LW} ; 172$ m.a.s.l.) during two consecutive seasons (2011/12 and 2012/13). The climate for this region is classified as Mediterranean semi-arid with an average daily temperature of $17.1^{\circ} \mathrm{C}$ and a mean annual rainfall of $679 \mathrm{~mm}$ (PobleteEcheverria et al., 2012). The summer period is usually cloudless, 
dry and hot and; only $2.2 \%$ of the annual rainfall occurs during this period, while spring is considered wet ( $16 \%$ of the annual rainfall occurs during this period). The spatial variability of soil at the experimental plot was very small with effective rooting depth and water holding capacity ranging between $55-60 \mathrm{~cm}$ and $124-135 \mathrm{~mm}$, respectively. The soil is classified as a Talca series (fine, mixed, thermic Ultic Haploxeralfs) with a clay loam texture and an average bulk density of $1.5 \mathrm{~g} \mathrm{~cm}^{-3}$. At the effective rooting depth, the volumetric soil water content at field capacity and the wilting point were 0.30 and $0.15 \mathrm{~m}^{3} \mathrm{~m}^{-3}$, respectively. The vineyard was irrigated using a single dripper per vine $\left(4 \mathrm{~L} \mathrm{~h}^{-1}\right)$. The Carménère vines were grafted on 1103 Paulsen rootstocks and planted in 2008 in a north-south orientation in rows separated by $2.5 \mathrm{~m}$, and the distance between vines was $1 \mathrm{~m}$. The grapevines were trained on a vertical shoot-positioned (VSP) system, with the main wire located at $1 \mathrm{~m}$ above ground level. The shoots were maintained in a vertical plane by two wires, with the highest one located $1.5 \mathrm{~m}$ above ground level.

\section{Weather Variables}

Standard weather variables, collected from an automatic meteorological station (Adcon Telemetry, A730, Klosterneuburg, Austria) located near the experimental site $(500 \mathrm{~m})$, were used to calculate the reference evapotranspiration $\left(\mathrm{ET}_{0}\right)$ over a wellirrigated grass. Air temperature $\left(\mathrm{T}_{\mathrm{a}}\right)$, relative humidity $(\mathrm{RH})$, solar radiation $\left(\mathrm{R}_{\mathrm{s}}\right)$, precipitation $\left(\mathrm{P}_{\mathrm{P}}\right)$, wind speed $\left(\mathrm{W}_{\mathrm{s}}\right)$, and wind direction $\left(\mathrm{W}_{\mathrm{d}}\right)$ were measured at $30 \mathrm{~min}$ time from May 1st to April 30th during each season. The $\mathrm{ET}_{\mathrm{a}}$ was calculated by adjusting the $\mathrm{ET}_{0}$ computed using the Penman-Monteith model by the crop coefficient $\left(K_{\mathrm{c}}\right)$ corresponding to each phenological stage (Allen et al., 1998). The $K_{c}$ values used in this study for Carménère vines were $0.11,0.24,0.61$, and 0.49 for the budburst, fruit set, veraison and near-harvest periods, respectively (JaraRojas et al., 2015). To characterize the effects of weather conditions on grapevine phenology at the experimental site, the thermal time was calculated as growing degree days (GDD):

$$
\mathrm{GDD}=\sum_{\mathrm{i}=1}^{\mathrm{n}} \frac{\operatorname{Tmax}+\operatorname{Tmin}}{2}-\mathrm{T}_{\text {base }}
$$

where $\mathrm{T}_{\max }$ and $\mathrm{T}_{\min }$ are daily maximum and minimum temperatures $\left({ }^{\circ} \mathrm{C}\right)$, respectively, and $\mathrm{T}_{\text {base }}$ is the base temperature $\left(10^{\circ} \mathrm{C}\right)$.

\section{Experimental Design}

The experimental design consisted of the implementation of three irrigation strategies with four replicates per treatment in a completely randomized design (CRD). This design was selected because the experiment was stablished in a vineyard block with uniform soil and vine canopy. In the experimental site, there were not significant differences among treatments for trunk diameter with values ranging between 41.4 and $41.6 \mathrm{~mm}$ (Table 1). The experimental unit corresponded to six adjacent vines. Irrigation was maintained at $100 \%$ of $\mathrm{ET}_{\mathrm{a}}$ from budbreak (B) to fruit set (S) during both seasons. The first irrigation strategy (T1) involved continuous irrigation at $100 \%$ of $\mathrm{ET}_{\mathrm{a}}$ from $\mathrm{S}$ to veraison $(\mathrm{V})$ and at $80 \%$ of $\mathrm{ET}_{\mathrm{a}}$ from $\mathrm{V}$ to harvest $(\mathrm{H})$; the second irrigation strategy (T2) involved irrigation at $50 \%$ of $\mathrm{ET}_{\mathrm{a}}$ from $\mathrm{S}$ to $\mathrm{H}$; and
TABLE 1 | Water application as a percentage of actual evapotranspiration ( $\left.E T_{a}\right)$.

\begin{tabular}{lccc}
\hline Irrigation strategies & S-V (\%) & V-H (\%) & TD (mm) \\
\hline T1 & 100 & 80 & 41.4 \\
T2 & 50 & 50 & 41.4 \\
T3 & 0 & 30 & 41.6 \\
Significance & - & - & 0.94
\end{tabular}

Also, trunk diameter (TD) is included as a reference. S, setting; $V$, veraison; $H$, harvest. Values followed by the same letter are not significantly different (Tuckey $p \leq 0.05)$.

the third irrigation strategy (T3) involved no-irrigation from $\mathrm{S}$ to $\mathrm{V}$ and at $30 \%$ of $\mathrm{ET}_{\mathrm{a}}$ from $\mathrm{V}$ to $\mathrm{H}$ (Table $\mathbf{1}$ ).

\section{Plant Water Status and Leaf Gas Exchange Measurements}

To evaluate vine water status, $\Psi_{\mathrm{s}}$ was measured weekly around midday (between 13 and $15 \mathrm{~h}$ ) (Coordinated Universal Time UTC-3) using a pressure chamber (PMS Instrument Company, Model 1000 Pressure Chamber Instrument). For this purpose, two mature healthy non-damaged leaves per replicate were selected and measured (Choné et al., 2001). Each selected leaf (still attached to the vine) was wrapped with plastic transparent film and covered with aluminum foil at least $2 \mathrm{~h}$ before being measured. By reducing leaf transpiration to near zero (plastic) and avoiding overheating (aluminum), this process allowed the water potential to equilibrate between the leaf and xylem of the plant.

To determine the accumulative effects of water deficit, integral water stress $\left(\mathrm{SI}_{\Psi}\right)$ was calculated as follows (Myers, 1988):

$$
\mathrm{SI} \Psi=\sum\left(\bar{\Psi}_{\mathrm{s}}-\mathrm{c}\right) \mathrm{n}
$$

where $\Psi_{\mathrm{s}}$ is the average of stem water potential for any interval $(\mathrm{MPa}), c$ is the maximum stem water potential value $(-0.4 \mathrm{MPa}$ for both seasons) during the whole period and $n$ is the number of days between measurements.

Measurements of photosynthetically active radiation (PAR), net $\mathrm{CO}_{2}$ assimilation $\left(\mathrm{A}_{\mathrm{N}}\right)$, stomatal conductance $\left(\mathrm{g}_{\mathrm{s}}\right)$, and leaf transpiration (E) were measured in parallel with $\Psi_{\mathrm{S}}$ on the same vines using a portable infrared gas analyzer (LI6400, LI-COR Inc., Lincoln, Nebraska, United States). For this purpose, another two mature healthy fully expanded and sunlit leaves were selected. During measurements, the leaf chamber temperature block was maintained between 25 and $32^{\circ} \mathrm{C}$, which was within the range of air temperatures of the measurement days. The molar air flow rate inside the leaf chamber was set to $500 \mu \mathrm{mol} \mathrm{mol}{ }^{-1}$. All measurements were taken at a reference $\mathrm{CO}_{2}$ concentration similar to that of the environment at the time of measurements (380-400 $\mu \mathrm{mol} \mathrm{mol}^{-1}$ ) and with a natural saturating photosynthetic photon flux that ensured leaves received more than $1,000 \mu \mathrm{mol} \mathrm{m}^{-2} \mathrm{~s}^{-1}$, as the leaf angle at the time of measurement was preserved (no external light source was used in this study) (Poni et al., 2014; Jara-Rojas et al., 2015). The intrinsic WUE $\left(W_{U E}=A_{N} / g_{s}\right)$, instantaneous WUE $\left(\mathrm{WUE}=\mathrm{A}_{\mathrm{N}} / \mathrm{E}\right), \mathrm{A}_{\mathrm{N}} / \mathrm{A}_{\mathrm{Nmax}}, \mathrm{g}_{\mathrm{s}} / \mathrm{g}_{\mathrm{smax}}$ and $\mathrm{E} / \mathrm{E}_{\max }$ ratios were 
estimated with the aim of standardizing the degree of change in comparison to the maximum values ( $A_{N \max }, g_{s \max }$, and $E_{\max }$ ) obtained from all treatments during each season.

\section{Yield Components and Soluble Solids}

The total yield (Yield; kg plant ${ }^{-1}$ ) was determined from the four central vines of each experimental unit, which were completely harvested at the same time as were those commercially harvested. The number of clusters (N_clusters) were registered for each vine harvested. A sample of 30 clusters from each replicate was selected to determine cluster weight (W_clusters), cluster volume (V_clusters) and the number of grapes per cluster (N_grapes). A sample of 100 randomized grapes per replicate was taken to determine grape weight (W_grapes) and grape diameter (D_grapes) (Acevedo-Opazo et al., 2010; Romero et al., 2015).

\section{Statistical Analysis}

A regression analysis was used to evaluate the effects of the different levels of vine water stress on the degree of association between the studied variables $\left(A_{N} / A_{N \max } v s g_{s}, \Psi_{s}\right.$ vs $g_{s}, W U E i$ vs $g_{s}$, WUE vs $g_{s}$, and WP vs $\left.S I \Psi\right)$. Additionally, the Root Mean Square Error (RMSE) and the Sum of the Squared Error (SSE) were calculated.

A piecewise linear regression (PLR) was performed to obtain the threshold values of the $g_{s}$ responses to water stress in the $A_{N} / A_{N m a x} v s g_{s}$ relationship (Toms and Lesperance, 2003; Malash and El-Khaiary, 2010). In this case, the PLR method was used to evaluate the existence of abrupt changes in slope (or the ratio of $A_{N} / A_{N \max }$ to $g_{s}$ ).

In addition, principal component analysis (PCA) was used to obtain a hierarchy of the variables analyzed to find patterns in the data and to classify any combination of variables that could explain the effects of irrigation treatments on $\mathrm{SI}_{\Psi}, \mathrm{WUE}, \mathrm{WUE}_{\mathrm{i}}$, WP and yield components. Finally, data for each parameter were obtained for each replicate per treatment and were subjected to two-way analysis of variance (ANOVA) to assess the influence of each irrigation strategy and season on the physiological and yield parameters. The variables analyzed for comparative purposes within treatments were $\Psi_{s}, A_{N} / A_{N \max }, g_{s} / g_{s m a x}, E / E_{\max }, W U E$, $\mathrm{WUE}_{\mathrm{i}}$, Yield, N_clusters, W_clusters, V_clusters, N_grapes, W_grapes, and D_grapes. The seasonality effects were estimated as "treatment $\times$ season" interactions. ANOVA was performed using the student version of the statistical software Infostat (National University of Cordoba, Argentina).

\section{RESULTS}

\section{Weather Conditions and Total Water Application}

In general, the atmospheric conditions during both seasons were dry and hot and without significant rainfall from $\mathrm{S}$ to $\mathrm{H}$ specifically for 2011/12 (Table 2), which is consistent with the climatic description for this region. There was only $66 \mathrm{~mm}$ of rainfall during the $2012 / 13$ season, with $77 \%$ concentrated during the S-V period. Additionally, the 2012/13 season had the highest amount of rainfall during the B-S period $(95.2 \mathrm{~mm})$. The mean air temperature ranged between 10 and $24^{\circ} \mathrm{C}$, while the VPD was between 0.2 and $1.7 \mathrm{kPa}$. The maximum and minimum average temperatures were between $35-36$ and $2-3^{\circ} \mathrm{C}$, respectively. The highest atmospheric demand occurred near the $\mathrm{V}$ period with values of $\mathrm{T}_{\mathrm{a}}$ between 15 and $24^{\circ} \mathrm{C}$ and VPD between 0.4 and $1.7 \mathrm{kPa}$. From $\mathrm{B}$ to $\mathrm{H}$, the accumulated values of $\mathrm{ET}_{0}$ were 925 and $880 \mathrm{~mm}$ while those of the GDD were 1,547 and $1,472^{\circ} \mathrm{C}$ for the $2011 / 12$ and 2012/13 growing seasons, respectively.

The total water applied ranged from $688 \mathrm{~m}^{3} \mathrm{ha}^{-1}$ for T3 during the $2012 / 13$ season to $2,692 \mathrm{~m}^{3} \mathrm{ha}^{-1}$ for $\mathrm{T} 1$ during the 2011/12 season (Table 3). For the two studied seasons, T3 received irrigation only during the $\mathrm{V}-\mathrm{H}$ period. The maximum water application was observed during $\mathrm{V}-\mathrm{H}$ period which presented the higher values of $\mathrm{ET}_{0}$ and $\mathrm{K}_{\mathrm{c}}$. The highest and lowest values of vine water status were observed during $\mathrm{S}-\mathrm{V}$ and $\mathrm{H}-\mathrm{V}$ periods, respectively. For the both seasons, values of $\Psi_{\mathrm{s}}$ for T1 ranged between -0.63 and $-1.01 \mathrm{MPa}$ while those for T3 were between -0.76 and $-1.53 \mathrm{MPa}$, respectively (Tables 4-6).

\section{Physiological Relationships}

Figure 1A shows a significant non-linear relationship between $\mathrm{A}_{\mathrm{N}} / \mathrm{A}_{\mathrm{Nmax}}$ vs $g_{\mathrm{s}}$ for the overall data set $\left(R^{2}=0.72 ; \mathrm{RMSE}=0.11\right.$ (dimensionless); $\mathrm{SEE}=0.17$ (dimensionless); and $p$-value $<0.01$; $n=304)$. In this study, the measured values of PAR, $A_{N}, g_{s}$, and $E$ near noon ranged between 1,100 and $1,900 \mu \mathrm{mol} \mathrm{m}^{-2} \mathrm{~s}^{-1}$, 1.4-19.0 $\mu \mathrm{mol} \mathrm{CO} \mathrm{m}^{-2} \mathrm{~s}^{-1}, 0.03-0.63 \mathrm{~mol} \mathrm{H}_{2} \mathrm{O} \mathrm{m}^{-2} \mathrm{~s}^{-1}$, and $0.8-11.8 \mathrm{mmol} \mathrm{m}^{-2} \mathrm{~s}^{-1}$, respectively. The maximum measured values of $A_{N}, g_{s}$, and $E$ for the $2011 / 12$ season were $14 \mu \mathrm{mol}$ $\mathrm{CO}_{2} \mathrm{~m}^{-2} \mathrm{~s}^{-1}, 0.36 \mathrm{~mol} \mathrm{H}_{2} \mathrm{O} \mathrm{m}^{-2} \mathrm{~s}^{-1}$ and $9.69 \mathrm{mmol} \mathrm{m}^{-2} \mathrm{~s}^{-1}$ while those for the $2012 / 13$ season were $19 \mu \mathrm{mol} \mathrm{CO}_{2}$

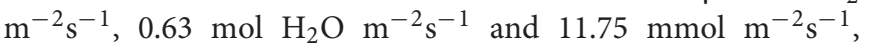
respectively.

Additionally, the piecewise linear regression analysis revealed that there were three main zones: $g_{s}>0.30$ (zone I; $\mathrm{A}_{\mathrm{N}} / \mathrm{A}_{\mathrm{Nmax}}=0.74$ ), $0.06<\mathrm{g}_{\mathrm{s}}<0.30$ (zone II; $\left.\mathrm{A}_{\mathrm{N}} / \mathrm{A}_{\mathrm{Nmax}}=0.26+1.74 \mathrm{~g}_{\mathrm{s}}\right)$ and $\mathrm{g}_{\mathrm{s}}<0.06 \mathrm{~mol} \mathrm{H}_{2} \mathrm{O} \mathrm{m} \mathrm{m}^{-2} \mathrm{~s}^{-1}$ (zone III; $\mathrm{A}_{\mathrm{N}} / \mathrm{A}_{\mathrm{Nmax}}=6.14 \mathrm{~g}_{\mathrm{s}}$ ) (Figure 1A). In zone I, $\mathrm{A}_{\mathrm{N}} / \mathrm{A}_{\mathrm{Nmax}}$ was not significantly affected by changes in $g_{s}$ and thus presenting a clear plateau $\left(R^{2}=0.10\right)$. For zones II and III, the $\mathrm{A}_{\mathrm{N}} / \mathrm{A}_{\mathrm{Nmax}}$ ratio decreased significantly when $g_{s}$ value diminished, the $R^{2}$ values were 0.22 and 0.26 , respectively. The estimated slopes were 6.1 and 1.7 per mol $\mathrm{H}_{2} \mathrm{O} \mathrm{m}^{-2} \mathrm{~s}^{-1}$ for zones II and III, respectively. For zone $I$, the mean value of $A_{N} / A_{N \max }$ was 0.81 $\left(\mathrm{A}_{\mathrm{N}}=13.4 \mu \mathrm{mol} \mathrm{CO} \mathrm{m}^{-2} \mathrm{~s}^{-1}\right)$ when $\mathrm{g}_{\mathrm{s}}$ decreased from 0.63 to $0.3 \mathrm{~mol} \mathrm{H}_{2} \mathrm{O} \mathrm{m}^{-2} \mathrm{~s}^{-1}$. The $\mathrm{A}_{\mathrm{N}} / \mathrm{A}_{\mathrm{Nmax}}$ values ranged between 0.18 and $1.0\left(\mathrm{~A}_{\mathrm{N}}\right.$ between 3.0 and $\left.16.6 \mu \mathrm{mol} \mathrm{CO} \mathrm{CO}^{-2} \mathrm{~s}^{-1}\right)$ and 0.10-0.45 ( $\mathrm{A}_{\mathrm{N}}$ between 1.7 and $\left.7.4 \mu \mathrm{mol} \mathrm{CO}_{2} \mathrm{~m}^{-2} \mathrm{~s}^{-1}\right)$ for zones II and III, respectively.

There was also a significantly non-linear relationship between $\Psi_{\mathrm{s}}$ and $\mathrm{g}_{\mathrm{s}}\left(R^{2}=0.5 ; \mathrm{RMSE}=0.09 \mathrm{~mol} \mathrm{H}_{2} \mathrm{O} \mathrm{m} \mathrm{m}^{-2} \mathrm{~s}^{-1}\right.$; $\mathrm{SEE}=0.07 \mathrm{~mol} \mathrm{H}_{2} \mathrm{O} \mathrm{m}^{-2} \mathrm{~s}^{-1} ; p$-value $<0.01$ ) (Figure 1B). In this case, the obtained threshold values of $g_{s}$ from the previous piecewise linear regression analysis $\left(0.30\right.$ and $0.06 \mathrm{~mol} \mathrm{H}_{2} \mathrm{O}$ $\mathrm{m}^{-2} \mathrm{~s}^{-1}$ ) were related to different levels of $\Psi_{\mathrm{s}}$. In this regard, the estimated $\Psi_{\mathrm{s}}$ thresholds were $\Psi_{\mathrm{s}}>-0.8 \mathrm{MPa}$ (zone I), $-0.8>\Psi_{\mathrm{s}}>-1.5 \mathrm{MPa}$ (zone II), and $\Psi_{\mathrm{s}}<-1.5 \mathrm{MPa}$ (zone III). 
TABLE 2 | Mean values of climate variable and water requirements for the main phenological stages of a drip-irrigated Carménère vineyard.

\begin{tabular}{|c|c|c|c|c|c|c|}
\hline Season/Phenological stages & & LF-B & B-S & S-V & $\mathbf{V}-\mathbf{H}$ & Season \\
\hline & $\mathrm{T}_{\mathrm{a}}\left({ }^{\circ} \mathrm{C}\right)$ & 8.2 & 14.9 & 20.5 & 17.5 & 13.4 \\
\hline & $\mathrm{ET}_{\mathrm{a}}(\mathrm{mm})$ & & 31.4 & 73.7 & 207.2 & 312 \\
\hline & $\mathrm{Pp}(\mathrm{mm})$ & 449.4 & 8.4 & 0 & 9.4 & 467 \\
\hline & $\operatorname{GDD}\left({ }^{\circ} \mathrm{C}\right)$ & 48 & 317.7 & 558.4 & 626.1 & 1,547 \\
\hline \multirow[t]{4}{*}{$2012 / 13$} & $\mathrm{ET}_{0}(\mathrm{~mm})$ & & 264.5 & 287.4 & 328.2 & 880 \\
\hline & $\mathrm{ET}_{\mathrm{a}}(\mathrm{mm})$ & & 30.6 & 71.1 & 196.6 & 298 \\
\hline & $\mathrm{Pp}(\mathrm{mm})$ & 416.4 & 95.2 & 50.8 & 15.2 & 578 \\
\hline & $\mathrm{GDD}\left({ }^{\circ} \mathrm{Cd}\right)$ & 59 & 339.4 & 494 & 580.5 & 1,473 \\
\hline
\end{tabular}

$L F$, leaf fall; $B$, Budburst; $S$, setting; $V$, veraison; $H$, harvest; VPD, vapor pressure deficit; $T_{a}$, air temperature; $P p$, rainfall; $E T_{0}$, reference evapotranspiration; $E T a$, actual evapotranspiration; $G D D$, growing degree days.

TABLE 3 | Water application $\left(\mathrm{m}^{3} \mathrm{ha}^{-1}\right)$ from setting $(\mathrm{S})$ to veraison $(\mathrm{V})$ and $\mathrm{V}$ to harvest $(\mathrm{H})$ for a drip-irrigated Carménère vineyard.

\begin{tabular}{|c|c|c|c|c|c|c|}
\hline \multirow{2}{*}{ Treatments } & \multicolumn{6}{|c|}{ Growing seasons } \\
\hline & \multicolumn{3}{|c|}{ 2011/12 } & \multicolumn{3}{|c|}{$2012 / 13$} \\
\hline T1 & 1,061 & 1,631 & 2,692 & 1,008 & 1,279 & 2,287 \\
\hline T2 & 526 & 1,036 & 1,562 & 509 & 983 & 1,491 \\
\hline
\end{tabular}

TABLE 4 | Effect of three levels of water application on physiological variables from setting (S) to veraison $(M)$ period of a drip-irrigated Carménère vineyard.

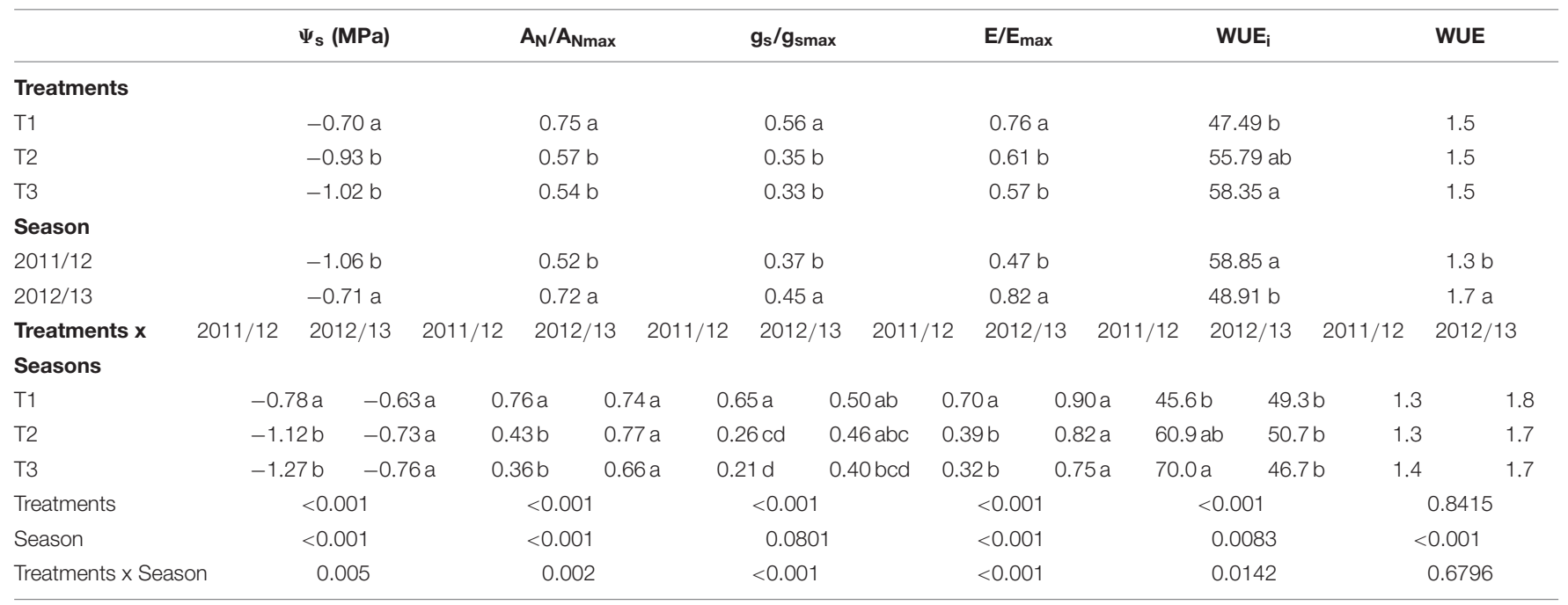

Values followed by the same letter are not significantly different (Tuckey $\mathrm{p} \leq 0.05)$. $\Psi_{S}$, midday stem water potential; $A_{N}$, net $\mathrm{CO}_{2}$ assimilation; $A_{N \text { max }}$, maximum net $\mathrm{CO} 2$ assimilation value (14 and $19 \mu \mathrm{mol} \mathrm{CO}_{2} \mathrm{~m}^{-2} \mathrm{~s}^{-1}$ for 2011/12 and 2012/13, respectively); $g_{s}$, stomatal conductance; $g_{s m a x}$, maximum stomatal conductance value (0.36 and $0.63 \mathrm{~mol} \mathrm{H}_{2} \mathrm{O} \mathrm{m}^{-2} \mathrm{~s}^{-1}$ for 2011/12 and 2012/13, respectively), E, transpiration; $E_{\text {max }}$, maximum transpiration value $\left(9.69\right.$ and $11.75 \mathrm{mmol} \mathrm{m}^{-2} \mathrm{~s}^{-1}$ for $2011 / 12$ and 2012/13, respectively); WUE , intrinsic water-use efficiency; WUE, water-use efficiency.

Figure $2 \mathrm{~A}$ indicates that there were significant linear correlations between WUEi and $\mathrm{g}_{\mathrm{s}}$ for Zone I and II with $R^{2}$ values of 0.67 and 0.51 , respectively. A large scattering of data was observed in the Zone III, which led to a not statistical significant relationship. Values of WUEi increased from 23.4 to $109.5 \mu \mathrm{mol} \mathrm{CO}_{2} / \mathrm{mol} \mathrm{H}_{2} \mathrm{O} \mathrm{m} \mathrm{m}^{-2} \mathrm{~s}^{-1}$ as $\mathrm{g}_{\mathrm{s}}$ diminished from 0.06 to $0.63 \mathrm{~mol} \mathrm{H}_{2} \mathrm{O} \mathrm{m} \mathrm{m}^{-2} \mathrm{~s}^{-1}$ (Zone I and II). Furthermore, there was not a statistical significant relationship between WUE vs $g_{s}$ for the three zones (Figure 2B). 
TABLE 5 | Effect of three levels of water application on physiological variables during veraison ( $V$ ) period of a drip-irrigated Carménère vineyard.

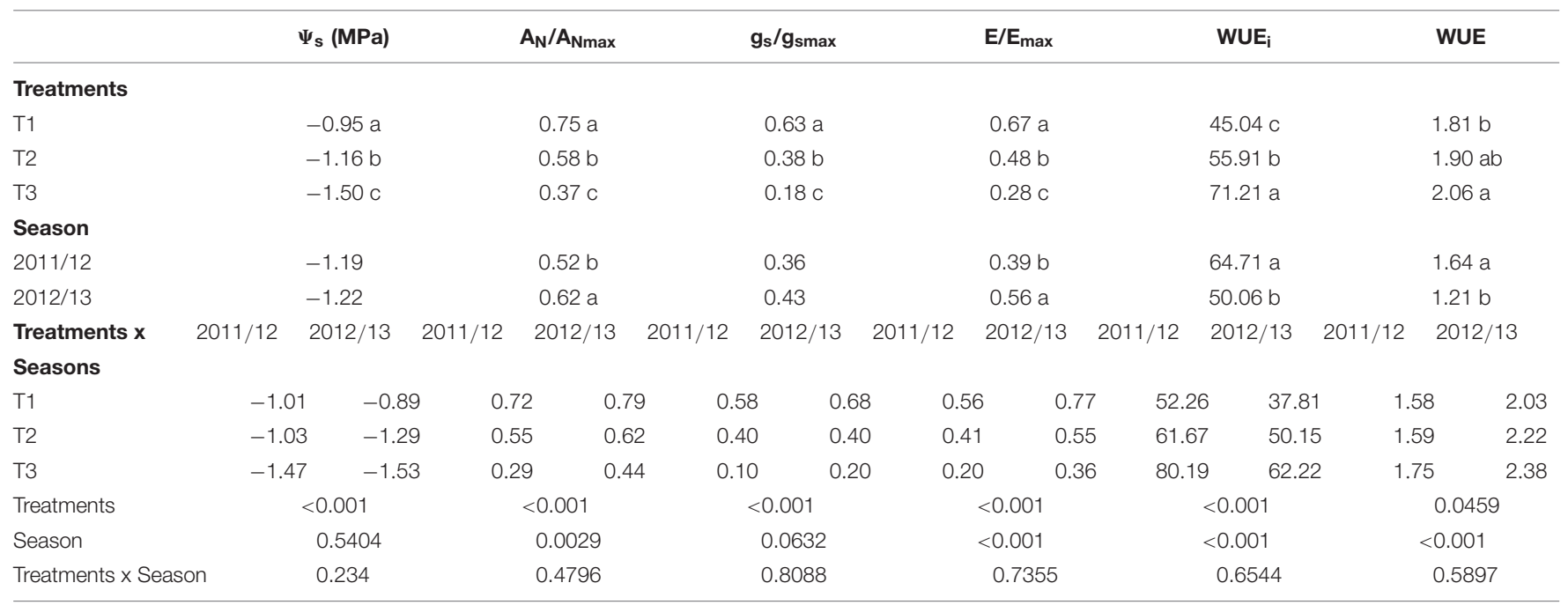

Values followed by the same letter are not significantly different (Tuckey $p \leq 0.05$ ). $\Psi_{s}$, midday stem water potential; $A_{N}$, net $\mathrm{CO}_{2}$ assimilation; $A_{N m a x}$, maximum net $\mathrm{CO}_{2}$ assimilation value (14 and $19 \mu \mathrm{mol} \mathrm{CO}_{2} \mathrm{~m}^{-2} \mathrm{~s}^{-1}$ for 2011/12 and 2012/13, respectively); $g_{s}$, stomatal conductance; $g_{\text {smax }}$, maximum stomatal conductance value (0.36 and $0.63 \mathrm{~mol} \mathrm{H}_{2} \mathrm{O} \mathrm{m}^{-2} \mathrm{~s}^{-1}$ for 2011/12 and 2012/13, respectively); E, transpiration; $E_{\max }$, maximum transpiration value $\left(9.69\right.$ and $11.75 \mathrm{mmol} \mathrm{m}^{-2} \mathrm{~s}^{-1} \mathrm{for} 2011 / 12 \mathrm{and}$ 2012/13, respectively); WUE, intrinsic water-use efficiency; WUE, water-use efficiency.

TABLE 6 | Effect of three levels of water application on physiological variables from veraison $(V)$ to harvest $(H)$ period on a Drip-irrigated Carménère vineyard.

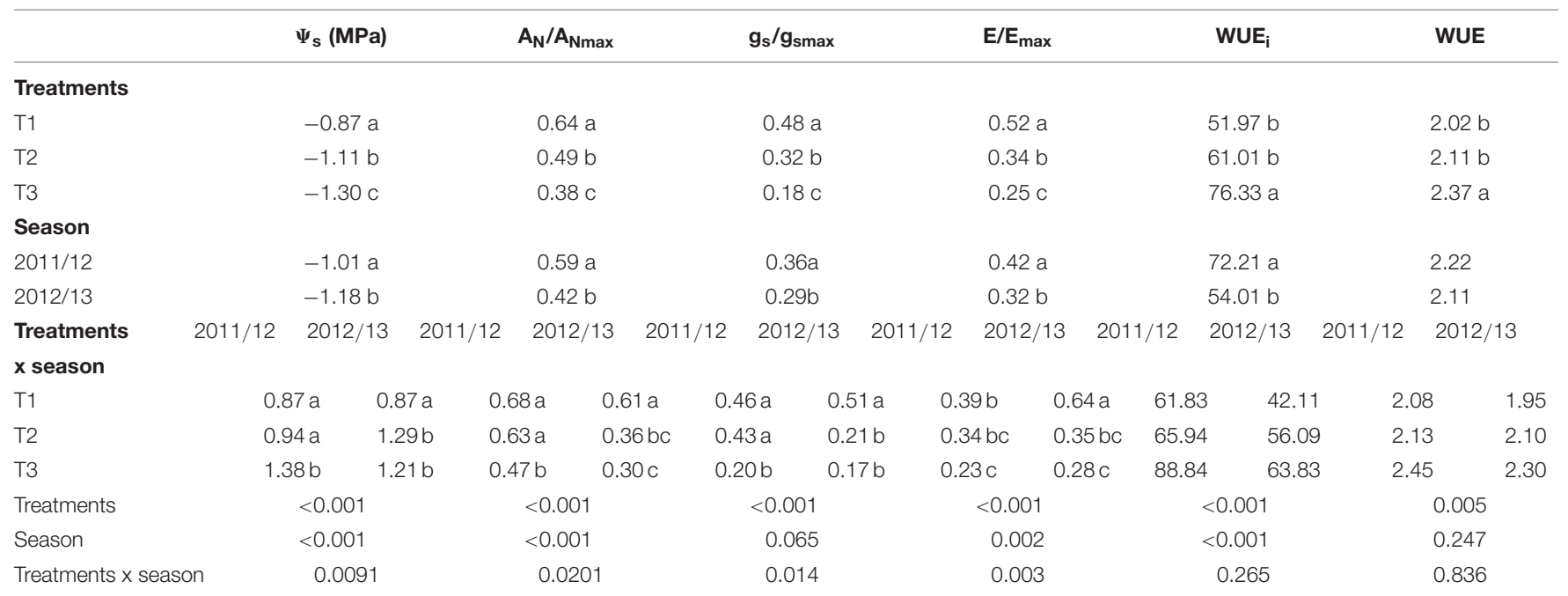

Values followed by the same letter are not significantly different (Tuckey $p \leq 0.05)$. $\Psi_{s}$, midday stem water potential; $A_{N}$, net $\mathrm{CO}_{2}$ assimilation; $A_{N \text { max }}$, maximum net $\mathrm{CO}_{2}$ assimilation value (14 and $19 \mu \mathrm{mol} \mathrm{CO}_{2} \mathrm{~m}^{-2} \mathrm{~s}^{-1}$ for 2011/12 and 2012/13, respectively); $g_{s}$, stomatal conductance; $g_{\text {smax }}$, maximum stomatal conductance value ( 0.36 and $0.63 \mathrm{~mol} \mathrm{H} \mathrm{O} \mathrm{m}^{-2} \mathrm{~s}^{-1}$ for 2011/12 and 2012/13, respectively); E, transpiration; Emax, maximum transpiration value $\left(9.69 \mathrm{mmol} \mathrm{m}^{-2} \mathrm{~s}^{-1} \mathrm{for} 2011 / 12\right.$ and $11.75 \mathrm{mmol} \mathrm{m} \mathrm{m}^{-2} \mathrm{~s}^{-1}$ for 2012/13); WUE

\section{PCA}

Principal component 1 (PC1) accounted for $70.73 \%$ of the variability; principal component 2 (PC2), 13.93\%. Therefore, the PCA presented in Figure 3 represents a total of $84.66 \%$ of the data variability. PC1 is positively related to the yield component variables (D_grapes, W_clusters, W_grape, Yield, and V_clusters, as well as N_grapes, albeit at a small percentage) that were best associated with T1. On the other hand, the PC2 was correlated with variables influenced positively by water stress (WP and $\mathrm{SI}_{\Psi}$ ). Therefore, PC2 was associated mainly with T2 and $\mathrm{T} 3$.

\section{Water Status Dynamics and Physiological Trends}

Tables 4-6 show the effects of three levels of water applications on physiological variables during the $\mathrm{S}-\mathrm{V}, \mathrm{V}$, and $\mathrm{V}-\mathrm{H}$ periods, respectively. Also, Supplementary Tables S1-S3 indicate a summary of analysis of variance (ANOVA) expressed on the mean square and degree of freedom (df) for physiological variables from setting $(\mathrm{S})$ to veraison $(\mathrm{V})$ period of a dripirrigated Carménère vineyard. For the $\mathrm{S}-\mathrm{V}$ period, significant interactions between irrigation treatments and seasons were observed for $\Psi_{s}, A_{N} / A_{N \max }, E / E_{\max }$, and $W_{U E}$. Results 


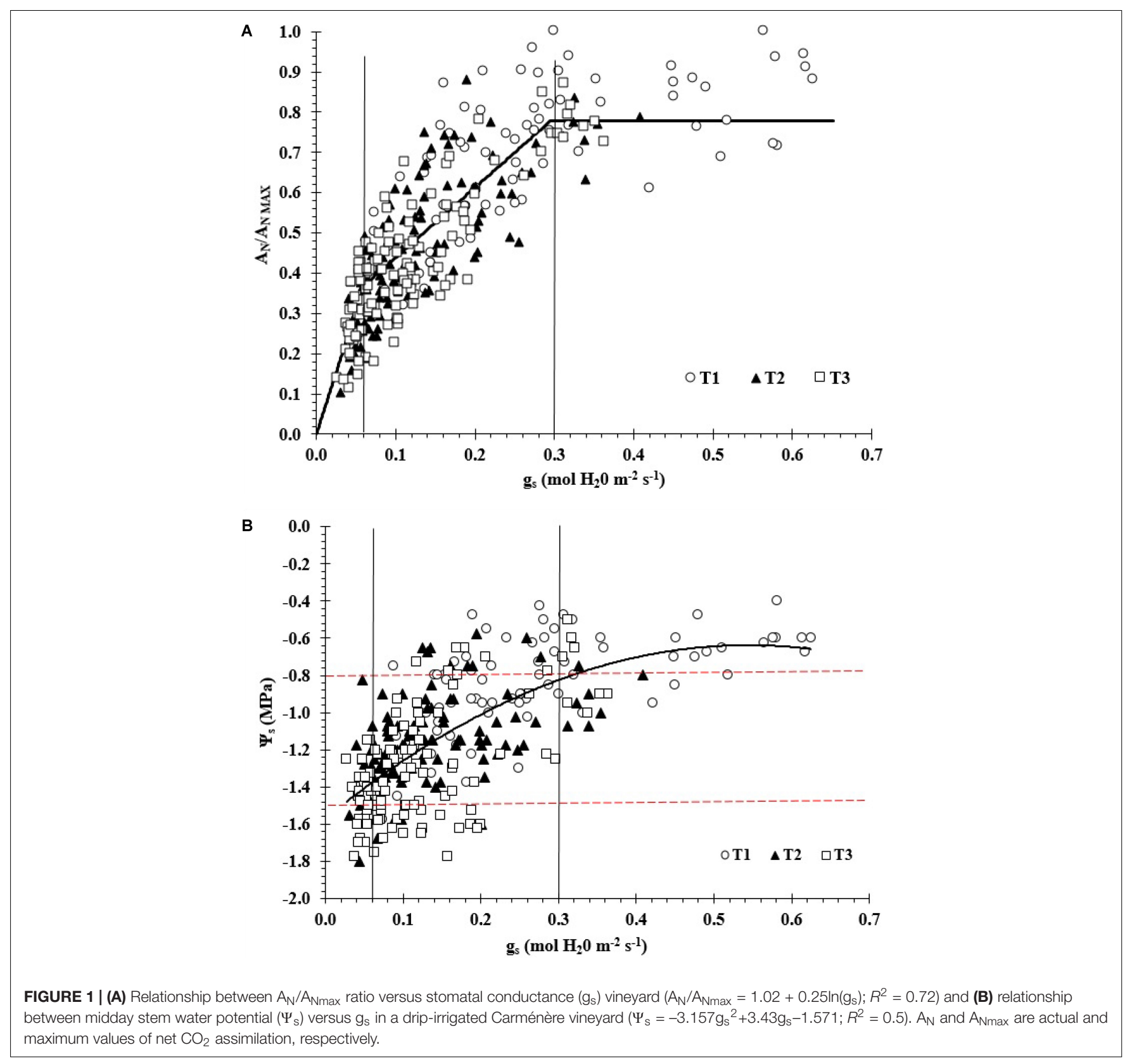

indicated that values of $\Psi_{\mathrm{s}}, \mathrm{A}_{\mathrm{N}} / \mathrm{A}_{\mathrm{Nmax}}$, and $\mathrm{E} / \mathrm{E}_{\max }$ for the $2011 / 12$ were significantly lower than those for $2012 / 13$. Also, there was a significant effect of water stress on vine water status and gas exchange where the highest values of $\Psi_{s}$, $A_{N} / A_{N \max }, g_{s} / g_{s \max }$, and $E / E_{\max }$ were observed in T1. For this treatment, mean values of $\Psi_{s}, A_{N} g_{s}$, and $\mathrm{E}$ for T1 were $-0.70 \mathrm{MPa}, 12.4 \mu \mathrm{mol} \mathrm{CO} \mathrm{m}^{-2} \mathrm{~s}^{-1}, 0.28 \mathrm{~mol} \mathrm{H}_{2} \mathrm{O} \mathrm{m} \mathrm{m}^{-2} \mathrm{~s}^{-1}$ and $8.15 \mathrm{mmol} \mathrm{m}^{-2} \mathrm{~s}^{-1}$, respectively, while those for T3 were $-1.5 \mathrm{MPa}, 6.1 \mu \mathrm{mol} \mathrm{CO} 2 \mathrm{~m}^{-2} \mathrm{~s}^{-1}, 0.09 \mathrm{~mol} \mathrm{H}_{2} \mathrm{O} \mathrm{m}^{-2} \mathrm{~s}^{-1}$ and $3.0 \mathrm{mmol} \mathrm{m}^{-2} \mathrm{~s}^{-1}$, respectively.

On the other hand, regarding T3 in the 2011/12 season, the $W_{U} E_{i}$ showed a significantly higher value than the other treatments with almost all interactions except with T2 for the
2011/12 season. Finally, the WUE showed significant differences only between years, and the value $\left(1.7 \mathrm{mmol} \mathrm{CO} \mathrm{mol} \mathrm{H}_{2} \mathrm{O}^{-1}\right)$ was higher in the 2012/13 study season than in the 2011/12 study season.

For the $V$ period, the mean values of $\Psi_{s}, A_{N} / A_{N \max }, g_{s} / g_{s m a x}$, and $\mathrm{E} / \mathrm{E}_{\max }$ for $\mathrm{T} 1$ were significantly higher than those observed for T2 and T3 (Table 5). In this case, mean values of $\Psi_{s}, A_{N} g_{s}$, and $\mathrm{E}$ for T1 were $-0.95 \mathrm{MPa}, 12.4 \mu \mathrm{mol} \mathrm{CO}_{2} \mathrm{~m}^{-2} \mathrm{~s}^{-1}, 0.31 \mathrm{~mol}$ $\mathrm{H}_{2} \mathrm{O} \mathrm{m}^{-2} \mathrm{~s}^{-1}$ and $7.2 \mathrm{mmol} \mathrm{m}^{-2} \mathrm{~s}^{-1}$ while those for T3 were $-1.5 \mathrm{MPa}, 6.1 \mu \mathrm{mol} \mathrm{CO} \mathrm{m}^{-2} \mathrm{~s}^{-1}, 0.09 \mathrm{~mol} \mathrm{H}_{2} \mathrm{O} \mathrm{m}^{-2} \mathrm{~s}^{-1}$ and $3.0 \mathrm{mmol} \mathrm{m}^{-2} \mathrm{~s}^{-1}$, respectively. For the same period, the mean values of WUE $\left(71.21 \mu \mathrm{mol} \mathrm{CO} \mathrm{Cm}^{-2} \mathrm{~s}^{-1} / \mathrm{mol} \mathrm{H}_{2} \mathrm{O} \mathrm{m}^{-2} \mathrm{~s}^{-1}\right)$ and WUE $\left(2.06 \mathrm{mmol} \mathrm{CO}_{2} / \mathrm{mol} \mathrm{H}_{2} \mathrm{O}^{-1}\right)$ for T3 were significantly 


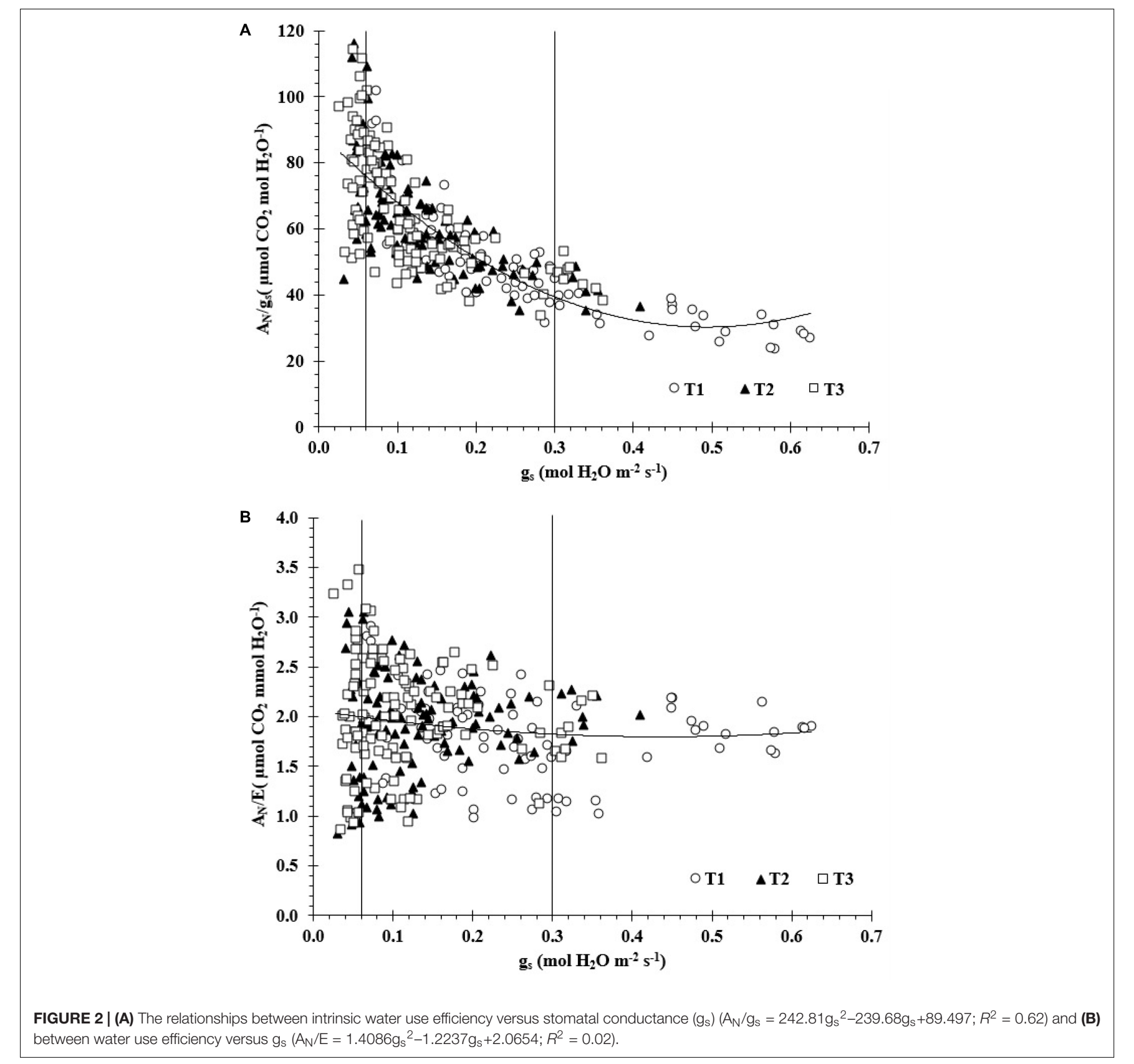

higher than those for the other treatments. Also, the $A_{N} / A_{N m a x}$ (0.62) and $E / E_{\max }(0.56)$ ratios for the $2012 / 13$ were significantly higher than those for the 2011/12 growing season; however, the lowest mean values of $\mathrm{WUE}_{\mathrm{i}}$ and $\mathrm{WUE}$ were observed during the 2012/13 growing season (Table 5).

For the V-H period, significant interactive effects of irrigation treatments and season were observed for $\Psi_{\mathrm{s}}, \mathrm{A}_{\mathrm{N}} / \mathrm{A}_{\mathrm{Nmax}}, \mathrm{g}_{\mathrm{s}} / \mathrm{g}_{\mathrm{smax}}$, and $\mathrm{E} / \mathrm{E}_{\max }$. For these parameters, T3 showed significantly lower mean values in comparison with T1 during both study seasons (Table 6). Results indicate that mean values of $\Psi_{s}$, $A_{N}, g_{s}$, and $E$ were significantly reduced by water stress from -0.87 to $-1.3 \mathrm{MPa}, 10.6-6.1 \mu \mathrm{mol} \mathrm{CO}_{2} \mathrm{~m}^{-2} \mathrm{~s}^{-1}, 0.24-0.09 \mathrm{~mol}$

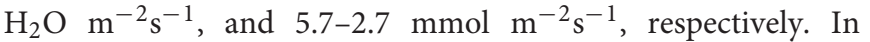
addition, mean values of $\mathrm{WUE}_{\mathrm{i}}$ and WUE for T3 were significantly higher than those for $\mathrm{T} 1$ and $\mathrm{T} 2$ and significantly higher during the 2011/12 than those during the 2012/13 season.

The results showed that the values of $\mathrm{WUE}_{\mathrm{i}}$ for $\mathrm{T} 1$ ranged between 23.4 and $73.3 \mu \mathrm{mol} \mathrm{CO}_{2} / \mathrm{mol} \mathrm{H}_{2} \mathrm{O} \mathrm{m} \mathrm{m}^{-2}$, for T2 ranged between 41.6 and $92.7 \mathrm{~mol} \mathrm{CO}_{2} / \mathrm{mol} \mathrm{H}_{2} \mathrm{O} \mathrm{m} \mathrm{m}^{-2} \mathrm{~s}^{-1}$, and for T3 ranged between 33.3 and $114.1 \mathrm{~mol} \mathrm{CO} / \mathrm{mol} \mathrm{H}_{2} \mathrm{O}$ $\mathrm{m}^{-2} \mathrm{~s}^{-1}$. The WUE values for $\mathrm{T} 1, \mathrm{~T} 2$, and $\mathrm{T} 3$ ranged from 0.98 to $2.9,0.94$ to 2.85 , and 0.86 to $3.5 \mu \mathrm{mol} \mathrm{CO} 2 / \mathrm{mol} \mathrm{H}_{2} \mathrm{O} \mathrm{m}^{-2} \mathrm{~s}^{-1}$, respectively. 


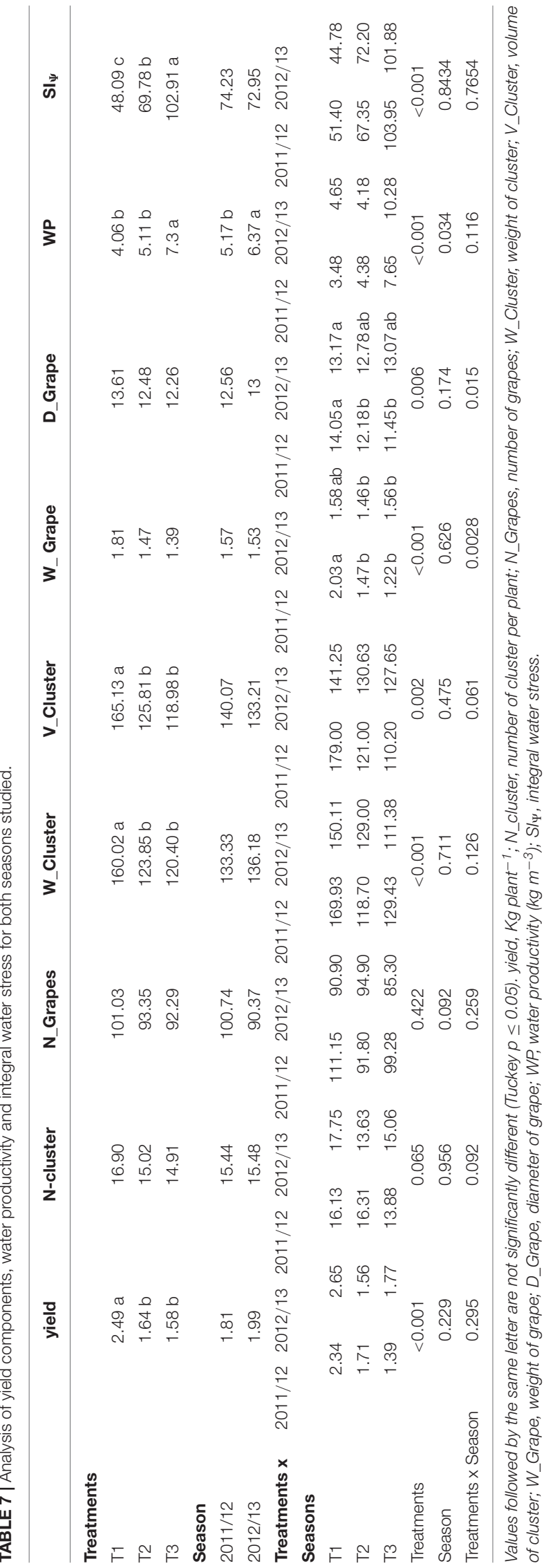

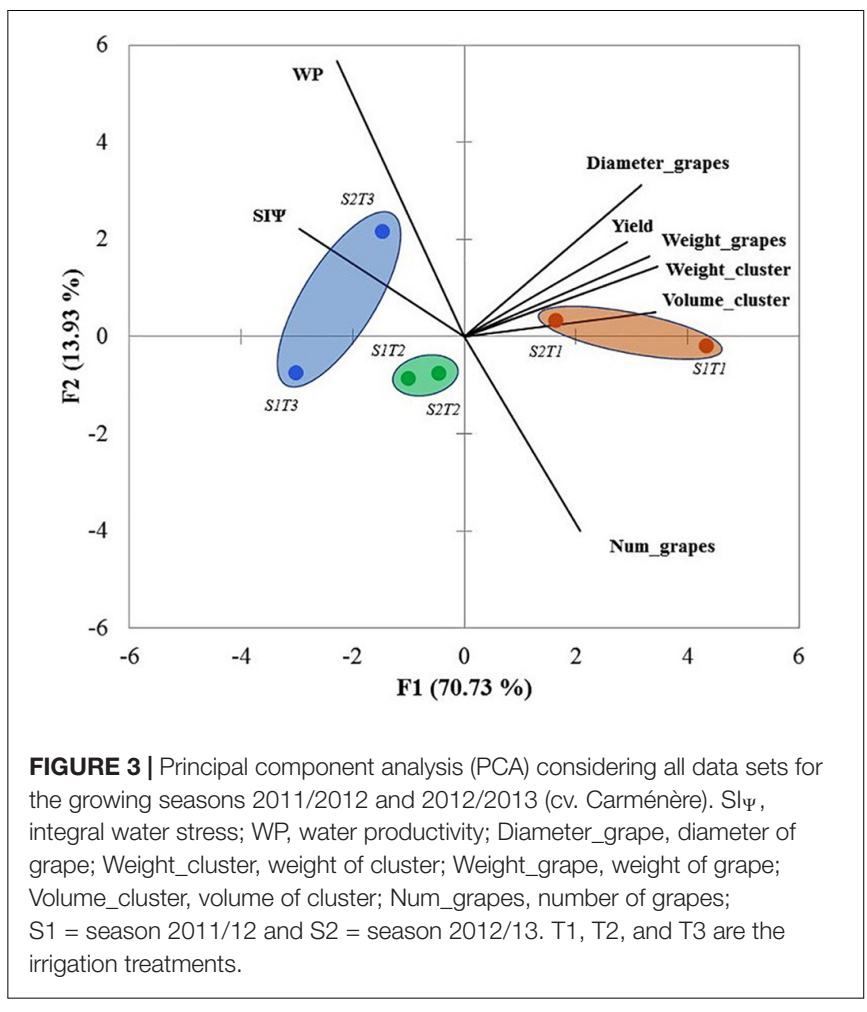

\section{Yield Components, Water Productivity, and Integral Water Stress Effects}

The results showed that there were significant differences among the irrigation strategies for yield, with the highest mean value observed for T1 $\left(2.49 \mathrm{~kg} \mathrm{plant}^{-1}\right)$ followed by T2 $(1.64 \mathrm{~kg}$ plant $^{-1}$ ) and T3 (1.58 kg plant ${ }^{-1}$ ), of which the last two did not show differences between them (Table 7). In this case, there were not significant difference, between treatments or between seasons for $\mathrm{N}_{\text {_clusters }}$ and $\mathrm{N} \_$grapes with mean values ranging between 14.90-16.90 and 92.29-101.03, respectively. W_clusters and $\mathrm{V}_{-}$clusters showed significantly higher mean values for T1 (160.02 gr and $165.13 \mathrm{~mL}$, respectively) compared to T2 (123.85 gr and $125.81 \mathrm{~mL}$, respectively) and T3 (120.40 gr and $118.98 \mathrm{~mL}$, respectively); the last two did not show significant differences between them. Significant interactive effects of irrigation treatments and season were observed for W_grapes and D_grapes. T1 presented the highest mean values, especially during the 2011/2012 season, compared to T2 and T3. For both studied seasons, $\mathrm{T} 2$ and $\mathrm{T} 3 \mathrm{did}$ not present significant differences between them (Table 7).

The average WP was significantly higher in $\mathrm{T} 3$ than $\mathrm{T} 1$ and $\mathrm{T} 2$; the mean value in $\mathrm{T} 3$ was $7.3 \mathrm{~kg} \mathrm{~m}^{-3}$. Furthermore, T1 $\left(4.06 \mathrm{~kg} \mathrm{~m}^{-3}\right)$ and T2 $\left(5.11 \mathrm{~kg} \mathrm{~m}^{-3}\right)$ did not present significant differences between them. Regarding the seasonality analysis, compared with the 2011/12 season, the 2012/13 season showed a significantly higher mean value of $6.37 \mathrm{~kg} \mathrm{~m}^{-3}$ (Table 7). In this study, SS measured at harvest, showed significant differences among treatments in soluble solids for $\mathrm{T} 2\left(25.8^{\circ} \mathrm{Brix}\right)$ and $\mathrm{T} 3$ $\left(25.7^{\circ}\right.$ Brix $)$ compared to $\mathrm{T} 1\left(24.5^{\circ}\right.$ Brix $)$ for the two seasons 


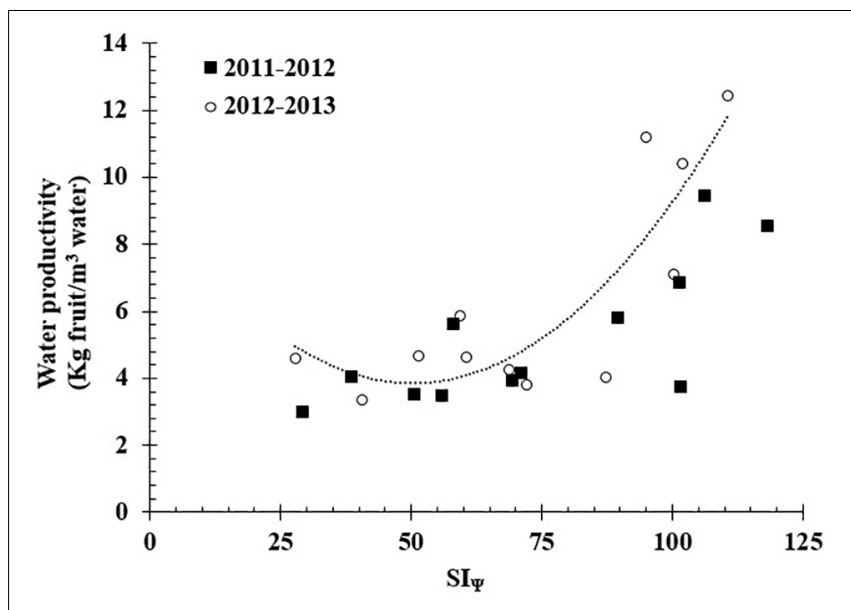

FIGURE 4 | Relationship between integral water stress (Sl $\Psi)$ and water productivity $\left(\mathrm{WP}=0.0022 S \mathrm{I}_{\Psi}{ }^{2}-0.2206 \mathrm{~S} \mathrm{I}_{\Psi}+9.396 ; R^{2}=0.74\right)$ in a grafted Carménère vineyard during the 2011/12 and 2012/13 growing season.

studied (data not shown). Finally, Supplementary Table S4 indicates a summary of an analysis of variance (ANOVA) expressed on the mean square and degree of freedom (df) for yield components, water productivity and integral water stress for both season studied.

The highest value of stem water potential (c) registered to calculate the SIY was $-0.4 \mathrm{MPa}$ for both studied seasons. The accumulative effect of water stress measured as SI $\Psi$ showed significant differences between all treatments; the highest mean values occurred for $\mathrm{T} 3(102.91 \mathrm{MPa})$, and the lowest mean values occurred for $\mathrm{T} 1$ (48.09 $\mathrm{MPa})$. Between seasons, the $\mathrm{SI} \Psi$ did not present significant differences. Finally, the $\mathrm{SI} \Psi$ presented a significant non-linear relationship $\left(R^{2}=0.74\right)$ with WP (Figure 4).

\section{DISCUSSION}

The weather conditions during the two study seasons were in accordance with those of the expected climatic description of the area. The cumulative ETa of the grafted cv. Carménère (298-312 $\mathrm{mm}$ ) observed in this study was close to that previously reported by Jara-Rojas et al. (2015) for an ungrafted cv. Carménère (315-349 mm) during $\mathrm{B}-\mathrm{H}$ period. For this period, the values of GDD ranged between 1,473 and $1,547^{\circ} \mathrm{C}$ which were similar to those reported for other red cultivars. In this regard, Verdugo-Vásquez et al. (2016) reported a range between 1,455 and $1,640^{\circ} \mathrm{C}$ for Cabernet Sauvignon while Ramos et al. (2018) indicated 1,358 and $1,483^{\circ} \mathrm{C}$ for cvs. Cabernet Sauvignon and Tempranillo, respectively.

In this experiment, the water application for $\mathrm{T} 2$ and $\mathrm{T} 3$ was between $38.3-65.2 \%$ and $26.7-30.1 \%$ of the $\mathrm{T} 1$ treatment, respectively. In this case, the mean seasonal values of $\Psi_{\mathrm{S}}$ were $-0.85,-1.1$, and $-1.3 \mathrm{MPa}$ for $\mathrm{T} 1, \mathrm{~T} 2$, and $\mathrm{T} 3$, respectively. The $\Psi_{\mathrm{S}}$ registered for the $\mathrm{S}-\mathrm{V}$ period showed that T1 experienced a weak water deficit whereas T2 and T3 showed moderate water stress. During the V period, T1 showed moderate water stress, whereas T2 and T3 showed moderate to severe and severe water stress, respectively. For the V-H period, T1 showed moderate water stress, whereas both T2 and T3 showed moderate and severe water stress (Tables 46) (Sibille et al., 2007; Van Leeuwen et al., 2009). The most significant effects of water restriction were observed for the $\mathrm{V}$ period, which showed significant differences between the three irrigation strategies and presented the maximum level of stress in T3 $(-1.50 \mathrm{MPa})$. The relatively low values of $\Psi_{\mathrm{s}}$ were similar to those reported by Intrigliolo et al. (2016) who reported values of approximately $-1.6 \mathrm{MPa}$ in rainfed treatments in $\mathrm{cv}$. Cabernet Sauvignon $(\approx 200 \mathrm{~mm}$ of rainfall during the season).

The maximum values of $\mathrm{A}_{\mathrm{N}}$ observed in this study (14.0$19.0 \mu \mathrm{mol} \mathrm{CO} \mathrm{m}^{-2} \mathrm{~s}^{-1}$ ) are similar to those presented by Flexas et al. (1999) and Prieto et al. (2010), who reported maximum $A_{N}$ values ranging between 20 and $21 \mu \mathrm{mol} \mathrm{CO}_{2} \mathrm{~m}^{-2} \mathrm{~s}^{-1}$. However, these values are higher than those reported by other studies involving different cultivars, where maximum $\mathrm{A}_{\mathrm{N}}$ values ranged between 15 and $16 \mu \mathrm{mol} \mathrm{CO} \mathrm{m}^{-2} \mathrm{~s}^{-1}$ (Romero et al., 2010; Poni et al., 2014; Jara-Rojas et al., 2015). In this case, mean values of $A_{N}$ were between $64-75,49-58$, and $37-54 \%$ of $A_{N \max }$ for T1, T2, and $\mathrm{T} 3$, respectively. The maximum reduction of $\mathrm{A}_{\mathrm{N}}$ was observed in $\mathrm{T} 3$ during $\mathrm{V}$ period.

Values of $\mathrm{g}_{\mathrm{s}}$ ranged between 0.0 and $0.63 \mathrm{~mol} \mathrm{H}_{2} \mathrm{O} \mathrm{m}^{-2} \mathrm{~s}^{-1}$ which are similar to those $\left(0-0.5 \mathrm{~mol} \mathrm{H}_{2} \mathrm{O} \mathrm{m}^{-2} \mathrm{~s}^{-1}\right)$ reported by Flexas and Medrano (2002) for cv. Manto Negro and Tempranillo. However, $g_{s}$ values of this study are higher than those reported by Romero et al. (2010), Prieto et al. (2010) and Chaves et al. (2007) who showed higher values of $g_{s}$ between 0.25 and $0.4 \mathrm{~mol} \mathrm{H}_{2} \mathrm{O} \mathrm{m} \mathrm{m}^{-2}$ for cv. Monastrell, Mourvèdre, Syrah, Marselan, Grenache, Ekigaïna, and Moscatel. In this study, mean values of $g_{s}$ were significantly reduced by water stress from 0.28 to $0.16,0.31$ to 0.09 , and 0.24 to $0.09 \mathrm{~mol} \mathrm{H}_{2} \mathrm{O} \mathrm{m} \mathrm{m}^{-2} \mathrm{~s}^{-1}$ for the $\mathrm{S}-\mathrm{V}, \mathrm{V}$ and $\mathrm{V}-\mathrm{H}$ periods, respectively.

Regarding reductions in photosynthesis due to stomatal closure, several authors have reported three phases of the photosynthetic response along a water stress gradient. In this case, $\mathrm{g}_{\mathrm{s}}<0.05,0.05<\mathrm{g}_{\mathrm{s}}<0.15$, and $\mathrm{g}_{\mathrm{s}}>0.15 \mathrm{~mol} \mathrm{H}_{2} \mathrm{O}$ $\mathrm{m}^{-2} \mathrm{~s}^{-1}$ are associated with severe, moderate and no water stress, respectively (Escalona et al., 1999; Flexas et al., 2002; Medrano et al., 2002; Cifre et al., 2005; Jara-Rojas et al., 2015). These ranges are in accordance with the piecewise linear regression analysis between $A_{N} / A_{N \max }$ versus $g_{s}$ observed in this study. However, the moderate and no water stress zones in this research showed differences in the thresholds and therefore in the range amplitude. Specifically, the upper level of the non-water stress conditions was for $g_{s}>0.30 \mathrm{~mol} \mathrm{~m}^{-2} \mathrm{~s}^{-1}$, where an increase of $g_{s}$ did not have a significant effect on the $A_{N} / A_{N m a x}$ trend (mean $A_{N}$ was about $76 \%$ of $A_{N \max }$ ). Furthermore, moderate stress occurred within the interval $0.06<\mathrm{g}_{\mathrm{s}}<0.30 \mathrm{~mol} \mathrm{~m}^{-2} \mathrm{~s}^{-1}$, which is wider than that reported in the literature. Moreover, the threshold of severe water stress was for $\mathrm{g}_{\mathrm{s}}<0.06 \mathrm{~mol} \mathrm{~m}^{-2} \mathrm{~s}^{-1}$ which remained very close to previously reported values for grapevines (Escalona 
et al., 1999; Flexas et al., 2002; Medrano et al., 2002; Cifre et al., 2005; Jara-Rojas et al., 2015).

In this study, the relationship between $\Psi_{s}$ and gs presented a large scattering. This variability could be associated with instantaneous weather variable changes (Rs, Ws, and VPD) or with a specific physiological behavior linked to the cv. Carménère (Flexas and Medrano, 2002; Jara-Rojas et al., 2015). Additionally, the results of the data analysis showed that stomatal closure for the Carménère cv. could be not associated exclusively with hydraulic signals and processes. This finding is supported by the observed stomatal behavior which show that stomata can remain partially opened even when vines are subjected to severe water stress levels $\left(\Psi_{s}=-1.5 \mathrm{MPa}\right)$, with $\mathrm{g}_{\mathrm{s}}$ values greater than $0.15 \mathrm{~mol} \mathrm{~m}^{-2} \mathrm{~s}^{-1}$. These results are in accordance with those reported by Jara-Rojas et al. (2015), who classified the cv. Carménère as drought tolerant. This effect has been confirmed for other cultivars such as Shiraz, in which applying restricted irrigation strategies resulted in increased WUE primarily via increased stomatal sensitivity to both water loss and VPD triggered by root-to-shoot hormone signaling, such as that involving abscisic acid (Collins et al., 2010).

The yield component analysis showed results similar to those of other RDI studies on grapevines. Specifically, the total yield was affected mainly because water stress reduced berry diameter and weight. Since there were no significant differences between T2 and T3, it is expected that grape size was affected mainly during the earliest stage of grape development (Acevedo-Opazo et al., 2010; Basile et al., 2011). Comparable results were reported by Santesteban et al. (2011) who observed that water stress at the beginning of berry development resulted in important reductions in berry weight. These reductions were not increased by applications of water stress in the period between $\mathrm{V}$ and H. In contrast to the results reported in this study, Chaves et al. (2007) did not report significant differences in yield between treatments irrigated at 100 and $50 \%$ of $\mathrm{ET}_{\mathrm{a}}$ in $\mathrm{cv}$. Castelao and Moscatel. In the same way, Trigo-Cordoba et al. (2015) reported no differences in yield for the cv. Godello under rainfed conditions and irrigation at $50 \%$ of $\mathrm{ET}_{\mathrm{a}}$. An explanation for these differences is related to levels of the water stress reached by the vines. The restricted irrigation treatments done by Chaves et al. (2007) and Trigo-Cordoba et al. (2015) only reached out a moderate water stress instead in our experiment Carménère vines were under moderate to severe water stress.

Similar to this study, Intrigliolo et al. (2016) found for cv. Cabernet Sauvignon that there were significant differences between rainfed conditions and irrigation at $75 \%$ of $\mathrm{ET}_{\mathrm{a}}$ during the $\mathrm{V}-\mathrm{H}$ period, with yields of 1.9 and $2.4 \mathrm{~kg} \mathrm{plant}^{-1}$, respectively. In this experiment, the WP was $2.7 \mathrm{~kg} \mathrm{~m}^{-3}$ under rainfed conditions and $1.7 \mathrm{~kg} \mathrm{~m}^{-3}$ at $75 \%$ of $\mathrm{ET}_{\mathrm{a}}$. These values of WP are lower than those observed in the present study, which were 4.0 and $7.3 \mathrm{~kg} \mathrm{~m}^{-3}$ for T1 and T3, respectively. These differences were strongly influenced by the amount of rainfall, which in the study reported by Intrigliolo et al. (2016) was approximately $150 \mathrm{~mm}$ higher during the growing season than the present study.
The SI $\Psi$ appeared to be an appropriate parameter for evaluating the effects of water deficit and its relationship with water productivity but did not show a good performance in terms of yield parameters (Zuñiga et al., 2017).

Although small decreases in the plant water potential could cause stomatal closure and a decrease in the intensity of $\mathrm{CO}_{2}$ assimilation, there are several physiological and molecular mechanisms that differentiate the level of the damage caused by water stress. Diverse studies carried out in different "cultivasr" have shown that there is a differential expression of genes involved in photosynthesis and gas exchange process which are expressed when plants are affected by different abiotic stress such as: water stress, salt, iron, cold and even light quality (Do Amaral et al., 2016; Liu et al., 2016; Saha et al., 2016; Vineeth et al., 2016). These abiotic stress directly affect on WUE through the gene expression linked to Rubisco, photorespiration process and photosystems functioning. The gene expression presents a high variability among species and also within the same species. In this sense, Tortosa et al. (2016) in a study carried out on 23 cultivars (red and white) and 30 genotypes of Tempranillo found that there was a very high variability in $W_{U E}$ with coefficients of variation (CV) ranging between 26 and 32\%, respectively.

Finally, future research will evaluate the effect of RDI on grape and wine quality of $\mathrm{cv}$. Carménère grafted on different rootstocks. This issue is very important because the commercial harvest of this cultivar is determined by the phenolic maturity (minimum seed tannins, maximum anthocyanins) (Fredes et al., 2010) to minimize the perception of astringency and is not related to a specific soluble solids content.

\section{CONCLUSION}

The irrigation strategies implemented in this study had a significant effect on gas exchange variables, WUEi, WUE, WP and yield components in grafted Carménère grapevines. The physiological variables analyzed in this study were altered by the irrigation strategies and showed significant differences during the period between veraison and harvest. Number of clusters and number of berries were not affected by the irrigation strategies; however, the rest of the yield components were affected, with a significant reduction in yield per plant. In terms of water productivity, T3 presented the highest value $\left(7.3 \mathrm{~kg} \mathrm{~m}^{-3}\right)$, with a clear compensation effect regarding the use of less water (reduction in irrigation water of approximately 70\%) to support the yield. These results were consistent in both study seasons. In addition, it was possible to obtain a non-linear relationship between $\mathrm{SI}_{\Psi}$ and WP. The results indicated that for improving WUE without affecting yield is recommended to apply RDI from veraison period. The evidence indicates that Carménère is tolerant to water stress and that it could be an appropriate cultivar to consider under severe water stress conditions in future climate change scenarios. Further research is necessary to evaluate the response of $\mathrm{cv}$. Carménère grafted on different rootstocks to water stress conditions. 


\section{AUTHOR CONTRIBUTIONS}

SO-F and $\mathrm{MZ}$ conceived and designed the experiments. $\mathrm{MZ}$ performed the evaluations. SO-F, MZ, CR-B, SF, and CP-E analyzed the data and wrote the paper.

\section{FUNDING}

This study was supported by the Chilean government through the projects CONICYT "Programa Formación de

\section{REFERENCES}

Acevedo-Opazo, C., Ortega-Farias, S., and Fuentes, S. (2010). Effects of grapevine (Vitis vinifera L.) water status on water consumption, vegetative growth and grape quality: an irrigation scheduling application to achieve regulated deficit irrigation. Agric. Water Manag. 97, 956-964. doi: 10.1016/j.agwat.2010. 01.025

Ahumada-Orellana, L., Ortega-Farias, S., Searles, P., and Retamales, J. (2017). Yield and water productivity responses to irrigation cut-off strategies after fruit set using stem water potential thresholds in a super-high density olive orchard. Front. Plant Sci. 8:1280. doi: 10.3389/fpls.2017. 01280

Allen, R. G., Pereira, L. S, Raes, D., and Smith, M. (1998). Guidelines for Computing Crop Water Requirements. FAO Irrigation and Drainage Paper No. 56, Rome: Crop evapotranspiration.

Basile, B., Marsal, J., Mata, M., Vallverdú, X., Bellvert, J., and Girona, J. (2011). Phenological sensitivity of cabernet sauvignon to water stress: vine physiology and berry composition. Am. J. Enol. Vitic. 62, 452-461. doi: 10.5344/ajev.2011. 11003

Chaves, M. M., Maroco, J. P., and Pereira, J. S. (2003). Understanding plant responses to drought - from genes to the whole plant. Funct. Plant Biol. 30, 239-264. doi: 10.1071/fp02076

Chaves, M. M., Santos, T. P., Souza, C. R., Ortuño, M. F., Rodrigues, M. L., Lopes, C. M., et al. (2007). Deficit irrigation in grapevine improves water-use efficiency while controlling vigour and production quality. Ann. Appl. Biol. 150, 237-252. doi: 10.1111/j.1744-7348.2006.00123.x

Choné, X. C., Van Leeuwen, C., Dubourdieu, D., and Gaudillère, J. P. (2001). Stem water potential is a sensitive indicator of grape water status. Ann. Bot. 87, 477-483. doi: 10.1006/anbo.2000.1361

Cifre, J., Bota, J., Escalona, J. M., Medrano, H., and Flexas, J. (2005). Physiological tools for irrigation scheduling in grapevine (Vitis vinifera L.). Agric. Ecosyst. Environ. 106, 159-170. doi: 10.1016/j.agee.2004.10.005

Collins, M. J., Fuentes, S., and Barlow, E. W. R. (2010). Partial rootzone drying and deficit irrigation increase stomatal sensitivity to vapour pressure deficit in anisohydric Grapevines. Funct. Plant Biol. 37, 128-138. doi: 10.1071/ fp09175

Do Amaral, M. N., Arge, L. W. P., Benitez, L. C., Danielowski, R., da Silveira Silveira, S. F., da Rosa Farias, D., et al. (2016). Differential expression of photosynthesis-related genes and quantification of gas exchange in rice plants under abiotic stress. Acta Physiol. Plant. 38:153. doi: 10.1007/s11738-0162176-9

Escalona, J. M., Flexas, J., and Medrano, H. (1999). Stomatal and non-stomatal limitations of photosynthesis under water stress in field-grown Grapevines. Aust. J. Plant Physiol. 26:421. doi: 10.1071/pp99019

Fereres, E., Goldhamer, D., and Parsons, L. (2003). Irrigation water management of horticultural crops. HortScience 38, 1036-1042

Flexas, J. and Medrano, H. (2002). Drought inhibition of photosynthesis in C-3 plants: stomatal and non-stomatal limitations revisited. Ann. Bot. 89, 183-189. doi: $10.1093 / \mathrm{aob} / \mathrm{mcf0} 27$

Flexas, J., Bota, J., Escalona, J., Sampol, B., and Medrano, H. (2002). Effects of drought on photosynthesis in Grapevines under field conditions: an evaluation of stomatal and mesophyll limitations. Funct. Plant Biol. 29:461. doi: 10.1071/ pp01119
Capital Humano Avanzado" ( $\mathrm{N}^{\circ}$ 21130752), FONDEF $\left(\mathrm{N}^{\circ}\right.$ D10I1157) by the Universidad de Talca through the research program "Adaptation of Agriculture to Climate Change (A2C2)".

\section{SUPPLEMENTARY MATERIAL}

The Supplementary Material for this article can be found online at: https://www.frontiersin.org/articles/10.3389/fpls.2018.00992/ full\#supplementary-material

Flexas, J., Escalona, J. M., and Medrano, H. (1999). Water stress induces different levels of photosynthesis and electron transport rate regulation in Grapevines. Plant Cell Environ. 22, 39-48. doi: 10.1046/j.1365-3040.1999.00371.x

Fredes, C., Von Bennewitz, E., Holzapfel, E., and Saavedra, F. (2010). Relation between seed appearance and phenolic maturity: a case study using grapes cv. Carménère. Chil. J. Agric. Res. 70, 381-389. doi: 10.4067/S071858392010000300005

Fuentes, S., Bei, R., Pech, J., and Tyerman, S. (2012). Computational water stress indices obtained from thermal image analysis of grapevine canopies. Irrig. Sci. 30, 523-536. doi: 10.1007/s00271-012-0375-8

Girona, J., Mata, M., del Campo, J., Arbonés, A., Bartra, E., and Marsal, J. (2006). The use of midday leaf water potential for scheduling deficit irrigation in vineyards. Irrig. Sci. 24, 115-127. doi: 10.1007/s00271-005-0015-7

Goldhamer, D. A., and Beede, R. H. (2004). Regulated deficit irrigation effects on yield, nut quality and water-use efficiency of mature pistachio trees. J. Hortic. Sci. Biotechnol. 79, 538-545. doi: 10.1080/14620316.2004.11511802

Goldhamer, D. A., Viveros, M., and Salinas, M. (2006). Regulated deficit irrigation in almonds: effects of variations in applied water and stress timing on yield and yield components. Irrig. Sci. 24, 101-114. doi: 10.1007/s00271-0050014-8

González-Altozano, P., and Castel, J. R. (1999). Regulated deficit irrigation in 'Clementina de Nules' citrus trees, I. Yield and quality effects. J. Hortic. Sci. Biotechnol. 74, 706-713. doi: 10.1080/14620316.1999.11511177

Intrigliolo, D. S., and Castel, J. R. (2008). Effects of irrigation on the performance of Grapevine cv. Tempranillo in Requena, Spain. Am. J. Enol. Vitic. 59, 30-38.

Intrigliolo, D. S., Lizama, V., García-Esparza, M. J., Abrisqueta, I., and Álvarez, I. (2016). Effects of post-versions irrigation regime on cabernet sauvignon Grapevines in Valencia, Spain: yield and grape composition. Agric. Water Manag. 170, 110-119. doi: 10.1016/j.agwat.2015.10.020

Jara-Rojas, F., Ortega-Farías, S., Valdés-Gómez, H., and Acevedo-Opazo, C. (2015). Gas exchange relations of ungrafted Grapevines (cv. carménère) growing under irrigated field conditions. S. Af. J. Enol. Vitic. 36, 231-242. doi: 10.21548/362-956

Lampinen, B. D., Shackel, K., Southwick, S. M., and Olson, W. H. (2001). Deficit irrigation strategies using midday stem water potential in prune. Irrig. Sci. 20, 47-54. doi: 10.1007/s002710000028

Liu, T. D., Zhang, X. W., Xu, Y., Liu, S. Q., and Chen, X. W. (2016). Light quality modifies the expression of photosynthetic genes in maize seedlings. Photosynthetica 55, 360-367. doi: 10.1007/s11099-016-0227-5

Malash, G., and El-Khaiary, M. (2010). Piecewise linear regression: a statistical method for the analysis of experimental adsorption data by the intraparticlediffusion models. Chem. Eng. J. 163, 256-263. doi: 10.1016/j.cej.2010.07.059

Medrano, H., Escalona, J., Bota, J., Gulias, J., and Flexas, J. (2002). Regulation of photosynthesis of C-3 plants in response to progressive drought: stomatal conductance as a reference parameter. Ann. Bot. 89, 895-905. doi: 10.1093/aob/ mcf079

Medrano, H., Tomás, M., Martorell, S., Escalona, J., Pou, A., Fuentes, S., et al. (2015a). Improving water use efficiency of vineyards in semi-arid regions. A review. Agron. Sustain. Dev. 35, 499-517. doi: 10.1007/s13593-014-0280-z

Medrano, H., Tomás, M., Martorell, S., Flexas, J., Hernandez, E., Roselló, J., et al. (2015b). From leaf to whole-plant water use efficiency (WUE) in complex canopies: limitations of leaf WUE as a selection target. Crop J. 3, 220-228. doi: 10.1016/j.cj.2015.04.002 
Merli, M. C., Magnaninia, E., Gattia, M., Pireza, F. J., Buesa Pueyo, I., Intrigliolo, D. S., et al. (2016). Water stress improves whole-canopy water use efficiency and berry composition of cv. Sangiovese (Vitis vinifera L.) Grapevines grafted on the new drought-tolerant rootstock M4. Agric. Water Manag. 169, 106-114. doi: 10.1016/j.agwat.2016.02.025

McCarthy, M. G., Loveys, B. R., Dry, P. R., Stoll, M. (2002). “Regulated deficit irrigation and partial rootzone drying as irrigation deficit irrigation for reducing agricultural water use 157 management techniques for Grapevines": Deficit irrigation practices. FAO Water Reports No. 22. Rome: FAO, 79-87.

Möller, M., Alchanatis, V., Cohen, Y., Meron, M., Tsipris, J., Naor, A., et al. (2006). Use of thermal and visible imagery for estimating crop water status of irrigated grapevine. J. Exp. Bot. 58, 827-838. doi: 10.1093/jxb/erl115

Myers, B. J. (1988). Water stress integral-a link between short-term stress and long-term growth. Tree Physiol. 4, 315-323. doi: 10.1093/treephys/4.4.315

Ortega-Farias, S., Fereres, E., and Sadras, V. O. (2012). Special issue on water management in Grapevines. Irrig. Sci. 30, 335-337 doi: 10.1007/s00271-0120356-y

Pellegrino, A., Gozé, E., Lebon, E., and Wery, J. (2006). A model-based diagnosis tool to evaluate the water stress experienced by grapevine in field sites. Eur. J. Agron. 25, 49-59. doi: 10.1016/j.eja.2006.03.003

Poni, S., Galbignani, M., Magnanini, E., Bernizzoni, F., Vercesi, A., Gatti, M., et al. (2014). The isohydric cv. Montepulciano (Vitis vinifera L.) does not improve its whole-plant water use efficiency when subjected to pre-veraison water stress. Sci. Hortic. 179, 103-111. doi: 10.1016/j.scienta.2014.09.021

Poblete-Echeverria, C. Ortega-Farias, S., Zuñiga, M., and Fuentes, S. (2012). Evaluation of compensated heat-pulse velocity method to determine vine transpiration using combined measurements of eddy covariance system and microlysimeters. Agric. Water Manag. 109, 11-19. doi: 10.1016/j.agwat.2012. 01.019

Prieto, J., Lebon, E., and Ojeda, H. (2010). Stomatal behavior of different grapevine cultivars in response to soil water status and air water vapour pressure deficit. OENO One 44, 9-20. doi: 10.20870/oeno-one.2010.44.1.1459

Ramos, M. C., Jones, G. V., and Yuste, J. (2018). Phenology of tempranillo and cabernet-sauvignon varieties cultivated in the Ribera del Duero DO: observed variability and predictions under climate change scenarios. OENO One 52. doi: 10.20870/oeno-one.2018.52.1.2119

Rivero, R. M., Shulaev, V., and Blumwald, E. (2009). Cytokinin-dependent photorespiration and the protection of photosynthesis during water deficit. Plant Physiol. 150, 1530-1540. doi: 10.1104/pp.109.139378

Romero, P., Fernandez-Fernandez, J., and Martinez-Cutillas, A. (2010). Physiological thresholds for efficient regulated deficit-irrigation management in winegrapes grown under semiarid conditions. Am. J. Enol. Vitic. 61, 300-312.

Romero, P., Gil-Muñoz, R., del Amor, F. M., Valdés, E., Fernández, J. I., and Martinez-Cutillas, A. (2013). Regulated deficit irrigation based upon optimum water status improves phenolic composition in Monastrell grapes and wines. Agric. Water Manag. 121, 85-101. doi: 10.1016/j.agwat.2013. 01.007

Romero, P., Muñoz, R. G., Fernández-Fernández, J. I., del Amor, F. M., MartínezCutillas, A., and García-García, J. (2015). Improvement of yield and grape and wine composition in field-grown Monastrell grapevines by partial root zone irrigation, in comparison with regulated deficit irrigation. Agric. Water Managt. 149, 55-73. doi: 10.1016/j.agwat.2014.10.018

Ruiz-Sanchez, M. C., Domingo, R., and Castel, J. R. (2010). Review. Deficit irrigation in fruit trees and vines in Spain. Span. J. Agric. Res. 8(Suppl. 2), S5-S25. doi: 10.5424/sjar/201008s2-1343

Saha, P., Sade, N., Arzani, A., Rubio Wilhelmi, M. D. M., Coe, K. M., Li, B., et al. (2016). Effects of abiotic stress on physiological plasticity and water use of Setaria viridis (L.). Plant Sci. 251, 128-138. doi: 10.1016/j.plantsci.2016. 06.011

Santesteban, L. G., Miranda, C., and Royo, J. B. (2011). Regulated deficit irrigation effects on growth, yield, grape quality and individual anthocyanin composition in Vitis vinifera L. cv. 'Tempranillo'. Agric. Water Manag. 98, 1171-1179. doi: 10.1016/j.agwat.2011.02.011

Sepulveda-Reyes, D., Ingram, B., Bardeen, M., Zúñiga, M., Ortega-Farias, S., and Poblete-Echeverría, C. (2016). Selecting canopy zones and thresholding approaches to assess grapevine water status by using aerial and ground-based thermal imaging. Remote Sens. 8:822. doi: 10.3390/rs8100822

Sibille, I., Ojeda, H., Prieto, J., Maldonado, S., Lacapere, J. N., Carboneau, A. (2007). "Relation between the values of three pressure chamber modalities (midday leaf, midday stem and predawn water potential) of 4 grapevine cultivars in drought situation of the southern of france. Applications for the irrigation control," in Proceedings of 15th International Symposium of GESCO, ed B. Sladonja (Porec: The Institute of Agriculture and Tourism), 685-695.

Spreer, W., Nagle, M., Neidhart, S., Carle, R., Ongprasert, S., and Müller, J. (2007). Effect of regulated deficit irrigation and partial rootzone drying on the quality of mango fruits (Mangifera indica L., cv. 'Chok Anan'). Agric. Water Manag. 88, 173-180. doi: 10.1016/j.agwat.2006.10.012

Toms, J., and Lesperance, M. (2003). Piecewise regression: a tool for identifying ecological thresholds. Ecology 84, 2034-2041. doi: 10.1890/02-0472

Tortosa, I., Escalona, J. M., Bota, J., Tomás, M., Hernández, E., Escudero, E. G., et al. (2016). Exploring the genetic variability in water use efficiency: evaluation of inter and intra cultivar genetic diversity in Grapevines. Plant Sci. 251, 35-43. doi: 10.1016/j.plantsci.2016.05.008

Trigo-Cordoba, E., Bouzas-Cid, Y., Orriols-Fernández, I., and Mirás-Avalos, J. (2015). Effects of deficit irrigation on the performance of grapevine (Vitis vinifera L.) cv. 'Godello' and 'Treixadura' in Ribeiro, NW Spain. Agric. Water Manag. 161, 20-30. doi: 10.1016/j.agwat.2015.07.011

Uriarte, D., Intrigliolo, D., Mancha, L., Valdez, E., Gamero, E., and Prieto, M. (2016). Combined effects of irrigation regimes and crop load on 'Tempranillo'grape composition. Agric. Water Manag. 165, 97-107. doi: 10.1016/j.agwat.2015.11.016

Van Leeuwen, C., Tregoat, O., Choné, X., Bois, B., Pernet, D., and Gaudillère, J. P. (2009). Vine water status is a key factor in grape ripening and vintage quality for red Bordeaux wine. How can it be assessed for vineyard management purposes? OENO One 43, 121-134. doi: 10.20870/oeno-one.2009.43.3.798

Verdugo-Vásquez, N., Acevedo-Opazo, C., Valdés-Gómez, H., Araya-Alman, M., Ingram, B., García de Cortázar-Atauri, I., et al. (2016). Spatial variability of phenology in two irrigated grapevine cultivar growing under semi-arid conditions. Precis. Agric. 17, 218-245. doi: 10.1007/s11119-015-9418-5

Vineeth, T. V., Kumar, P., and Krishna, G. K. (2016). Bioregulators protected photosynthetic machinery by inducing expression of photorespiratory genes under water stress in chickpea. Photosynthetica 54, 234-242. doi: 10.1007/ s11099-016-0073-5

Williams, L. E., and Araujo, F. J. (2002). Correlations among predawn leaf, midday leaf, and stem water potential and their correlations with other measures of soil and plant water status in Vitis vinifera. J. Amer. Soc. Hort. Sci. 127, 448-454.

Zuñiga, M., Poblete-Echeverria, C., Riveros, C., and Ortega-Farias, S. (2017). Water stress integral as indicator of grape quality and yield parameters in a 'Carménère' vineyard with regulated deficit irrigation. Acta Hortic. (1150), 501-506. doi: 10.17660/actahortic.2017.1150.69

Conflict of Interest Statement: The authors declare that the research was conducted in the absence of any commercial or financial relationships that could be construed as a potential conflict of interest.

Copyright (c) 2018 Zúñiga, Ortega-Farías, Fuentes, Riveros-Burgos and PobleteEcheverría. This is an open-access article distributed under the terms of the Creative Commons Attribution License (CC BY). The use, distribution or reproduction in other forums is permitted, provided the original author(s) and the copyright owner(s) are credited and that the original publication in this journal is cited, in accordance with accepted academic practice. No use, distribution or reproduction is permitted which does not comply with these terms. 